\title{
Designed protein multimerization and polymerization for functionalization of proteins
}

\author{
Dani Permana $(\mathbb{D} \cdot$ Herlian Eriska Putra $\cdot$ Djaenudin Djaenudin
}

Received: 27 August 2021/ Accepted: 4 December 2021/Published online: 27 January 2022

(C) The Author(s), under exclusive licence to Springer Nature B.V. 2021

\begin{abstract}
Multimeric and polymeric proteins are large biomacromolecules consisting of multiple protein molecules as their monomeric units, connected through covalent or non-covalent bonds. Genetic modification and post-translational modifications (PTMs) of proteins offer alternative strategies for designing and creating multimeric and polymeric proteins. Multimeric proteins are commonly prepared by genetic modification, whereas polymeric proteins are usually created through PTMs. There are two methods that can be applied to create polymeric proteins: self-assembly and crosslinking. Self-assembly offers a spontaneous reaction without a catalyst, while the crosslinking reaction offers some catalyst options, such as chemicals and enzymes. In addition, enzymes are excellent catalysts because they provide
\end{abstract}

site-specificity, rapid reaction, mild reaction conditions, and activity and functionality maintenance of protein polymers. However, only a few enzymes are applicable for the preparation of protein polymers. Most of the other enzymes are effective only for protein conjugation or labeling. Here, we review novel and applicable strategies for the preparation of multimeric proteins through genetic modification and selfassembly. We then describe the formation of protein polymers through site-selective crosslinking reactions catalyzed by enzymes, crosslinking reactions of nonnatural amino acids, and protein-peptide (SpyCatcher/ SpyTag) interactions. Finally, we discuss the potential applications of these protein polymers.

D. Permana $(\bowtie)$

Faculty of Agriculture, Kyushu University, 744 Motooka,

Nishi-ku, Fukuoka 819-0395, Japan

e-mail: dani008@brin.go.id

D. Permana - H. E. Putra - D. Djaenudin

Research Unit for Clean Technology, The National

Research and Innovation Agency of Republic of

Indonesia, J1. Cisitu, Bandung 40135, Indonesia 


\section{Graphical abstract}

\section{Strategies for Multimerization and Polymerization of Proteins}

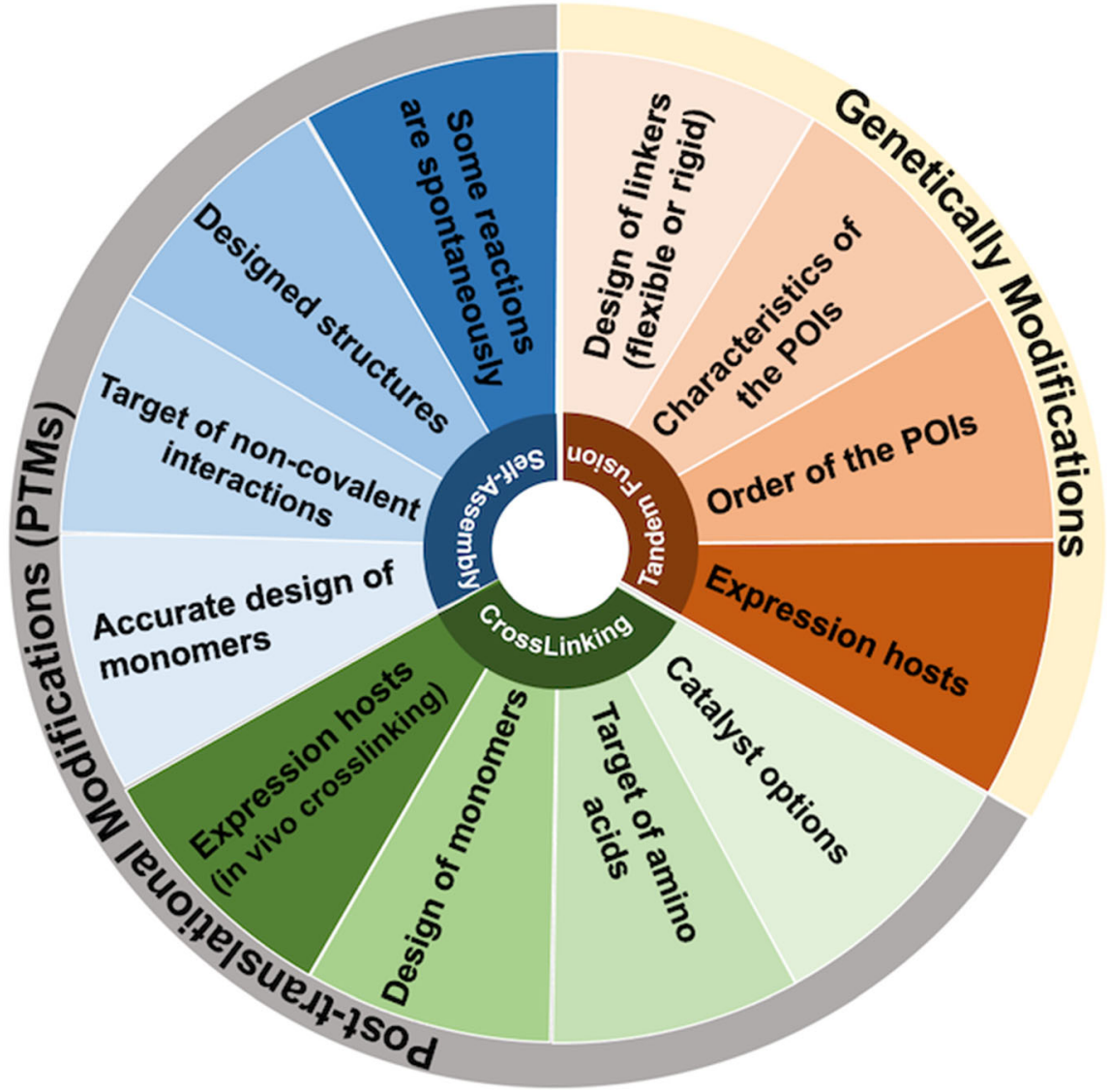

Keywords Protein functionalization · Protein polymerization · Protein polymers $\cdot$ Self-assembly . Crosslinking reaction

\section{Introduction}

Proteins are polymers of amino acids with specific structures and functions. In nature, some proteins are in a multimeric or polymeric form, which consists of a long-repeated unit and is known as an essential biological event. One example of a natural polymeric protein is resilin, a flexible protein commonly found in insects and first discovered by Weis-Fogh in the early 1960s (Fig. 1A-D) (Li and Kiick 2013; Su et al. 2014). It is formed naturally by tyrosine coupling, called dityrosine, which connects the monomer units of tyrosine-containing proteins (Fig. 1A) (Elvin et al. 2005; Li and Kiick 2013; Su et al. 2014; Partlow et al. 2016; Wang et al. 2016). Interestingly, resilin is also known as an elastomeric protein and is commonly found in the flea, helping them to jump more than 30 times higher than their body length (Fig. 1B). Moreover, a high number of dityrosine-rich resilin are also found in the wing tendons of dragonflies (Fig. 1C) and composite shelters of aquatic caddisfly larvae made from silk fibers, organic materials, and stones (Fig. 1D) (Partlow et al. 2016). The silk fibers of the 
A

C

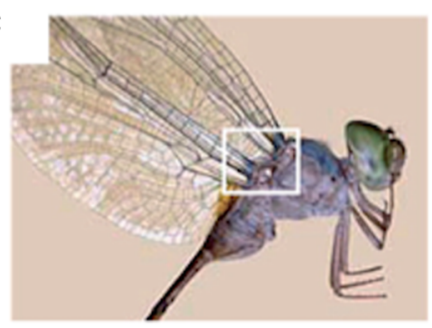<smiles>NC(Cc1ccc(O)c(-c2cc(CC(N)C(=O)O)ccc2O)c1)C(=O)O</smiles>

B
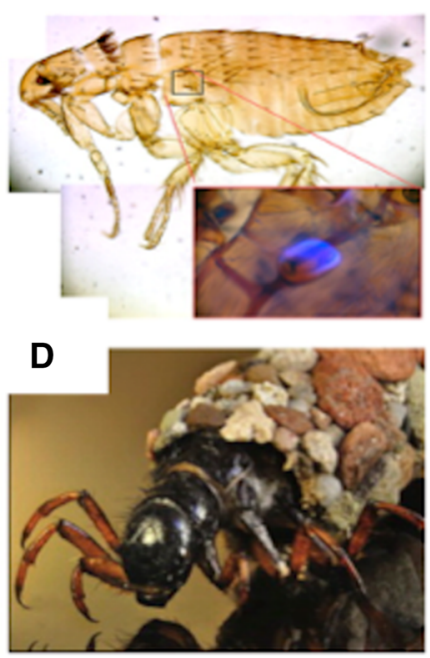

E

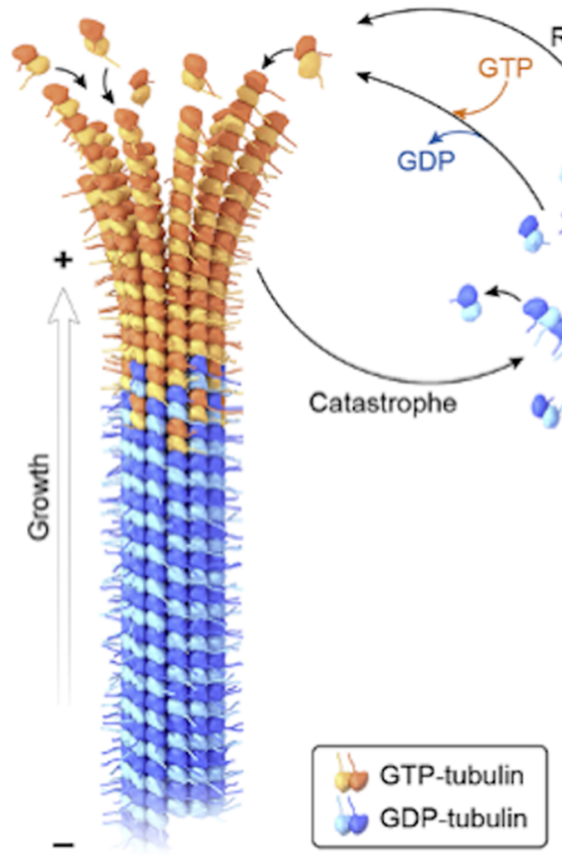

Fig. 1 Some examples of natural polymeric proteins. A The chemical structure of dityrosine bond discovered by Weis-Fogh when they reported their discovery on resilin. B Highlight of location of resilin in the flea. $\mathbf{C}$ The wing tendon from adult dragonfly (Zyxomma sp.) contains a large amount of dityrosine rich resilin. D A caddisfly (Hesperophylax occidentalis) larvae build composite shelters from adhesive silk fiber. The silk fibers of the caddisfly were identified as a polymeric heavy chain fibroin, which consists of a unique repeating motif. Reproduced from Partlow et al. (2016). Copyright 2016 with permission from the American Chemical Society (ACS). $\mathbf{E}$ The cycle of
$\mathbf{F}$

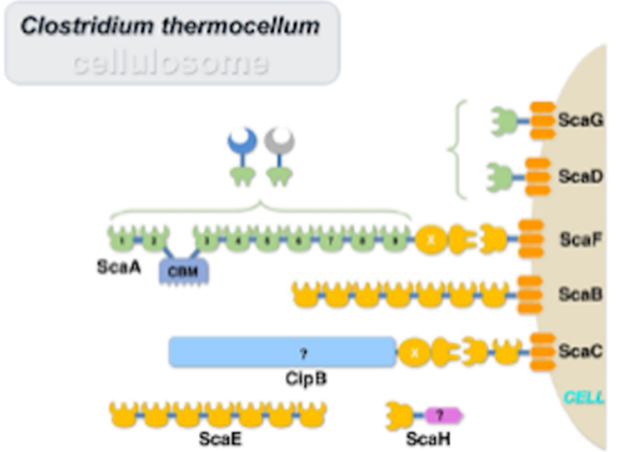

Acetivibrio cellulolyticus

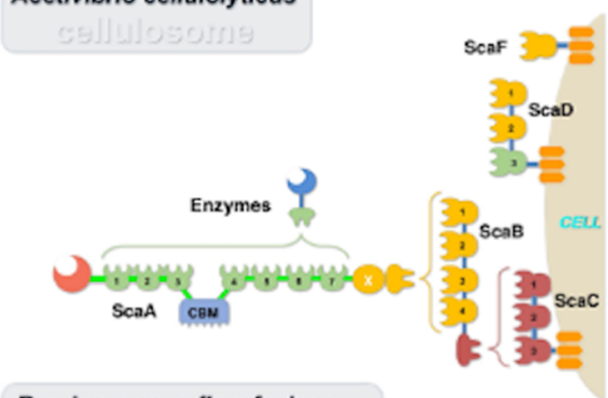

Ruminococcus flavefaciens FD.1

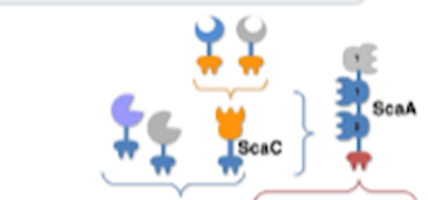

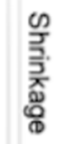

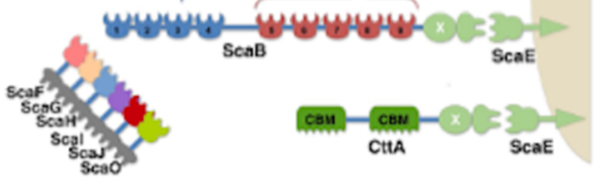

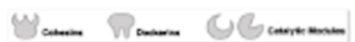

microtubules (MTs); growth and shrinkage (depolymerization). Catastrophe is the transition from growth to depolymerization. Rescue is the opposite transition. Reproduced from Roll-Mecak (2020). Copyright 2020 with permission from Elsevier. F The three different architectures of the cellulosomes from different species; Clostridium thermocellum, Acetivibrio cellulolyticum, and Ruminococcus flavefaciens. The different cohesins and dockerins (Coh-Doc) interactions and/or specificities are presented in different colors. Reproduced from Bule et al. (2018). Copyright 2018 with permission from Elsevier 
caddisfly were identified as a polymeric heavy chain fibroin, which consists of a unique repeating motif.

The structures of natural multimeric proteins are highly diverse, including rings, fibers, tubes, catenanes, cages, and knots (Pieters et al. 2016). Some proteins have the same functionality in both monomeric and multimeric architectures (Häkkinen et al. 2013; Janib et al. 2014). Commonly, multimeric proteins can be divided into homomultimeric and heteromultimeric proteins. This depends on the protein units of the multimeric proteins. If the protein units are the same, they are identified as homomultimeric proteins, whereas, if different, they are identified as heteromultimeric proteins (Hashimoto et al. 2011). Interestingly, multimeric proteins, especially homomultimeric proteins, can be found in the Protein Data Bank (PDB) database. Approximately 22\% of proteins in $\mathrm{PDB}$ are multimeric proteins. This suggests the abundance of natural multimeric proteins with specific structures and functions.

One of the most famous examples of natural polymeric proteins is microtubules (MTs) (Fig. 1E), which are polymers of tubulin and usually found in dividing eukaryotic cells. They are bound through non-covalent bonds, which can also be found in differentiated cells. The building blocks of MTs are heterodimers of tubulins, which consist of $\alpha$ - and $\beta$ tubulin (dark and light blue) (Fig. 1E) (Desai and Mitchison 1997; Roll-Mecak 2020). Furthermore, $\alpha \beta$ tubulins assemble to form a polar protofilament with $\alpha$-tubulin and $\beta$-tubulin exposed to different sides. Interestingly, $\beta$-tubulin was identified as capable of binding GTP and hydrolyzed after the incorporation of $\alpha \beta$-tubulins to form non-covalent cylindrical polymers, which are usually formed from at least 13 protofilaments. The transition from the growth state to the shrinking state (depolymerization) is called a catastrophe. Another interesting example is the cellulosome (Fig. 1F), a complex of multienzymes which bind to the anaerobic bacterial cell wall and help bacteria degrade complex cellulosic substrates. Some cellulosomes are multi-modular enzyme complexes that are usually found in anaerobic cellulolytic microorganisms. Cellulosomes play an important role in the degradation of recalcitrant polysaccharides to produce simple sugars, which are needed for bacteria as carbon sources (Bule et al. 2018; Tang et al. 2018; Kahn et al. 2019). Figure 1F presents the architecture of three different cellulosomes from different bacteria:

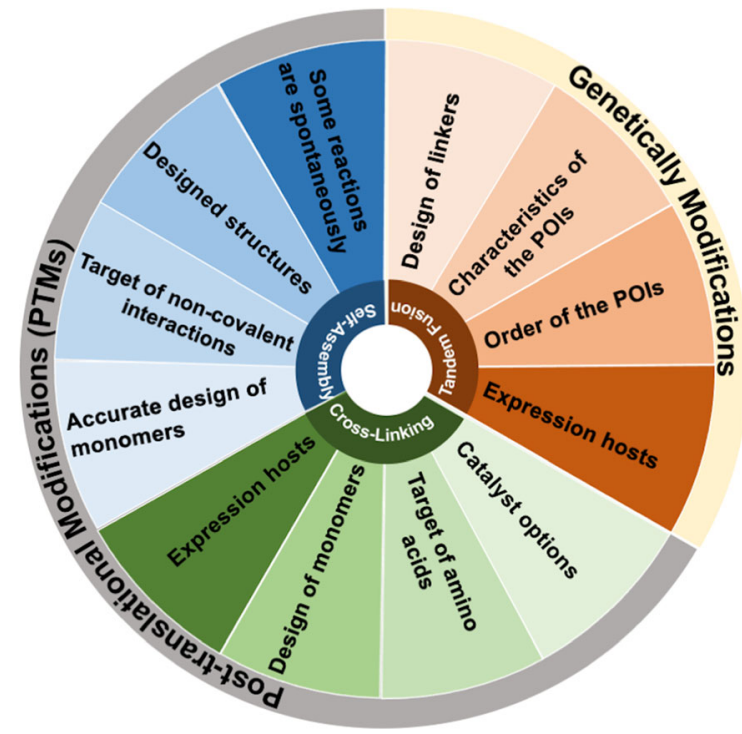

Fig. 2 Three common strategies for creating multimeric or polymeric proteins and its critical steps. Genetic modification through tandem fusion is commonly used for protein fusion. Two or more genes encoding proteins were fused and engineered into one expression cassette. Neither covalent nor noncovalent bond formations are involved in this method. Another two common strategies are crosslinking reactions and the self-assembly of proteins. Crosslinking of proteins is a method of joining proteins that can be prepared through in vivo or in vitro reactions. The formation of covalent bonds between protein units is commonly catalyzed by chemicals and enzymes. Self-assembly methods are also applicable for creating protein conjugates and polymers. It provides some options for noncovalent interactions to connect the protein units in the polymers

Clostridium thermocellum, Acetivibrio cellulolyticus, and Ruminococcus flavefaciens. The differences between them are the type of cohesin-dockerin (Coh-Doc) interactions. C. thermocellum has type I Docs, which makes it possible to display different orientations owing to its rotating capability. A. cellulolyticus provides some adaptor scaffoldings, Sca, that could improve the intricacy of cellulosome architecture and incorporation of a high number of enzymes. Lastly, to the best of our knowledge, the most complex cellulosome thus far is found in $R$. flavefaciens, which possesses more than 200 Doc-containing proteins and 21 Coh. Interestingly, the Docs and Cohs of $R$. flavefaciens's cellulosome are structurally divergent and unlikely to be type I to II of C. thermocellum and, thus, classified as type III (Bule et al. 2018). Moreover, in this system, monocovalent adaptor scaffoldings are unique proteins bound to a single Coh that diverges 
from its $C$-terminal Doc. The remarkable cellulosome complexity makes them even more interesting when the nature of its components is considered.

Inspired by nature, researchers are trying to create multimeric or polymeric proteins with specific specifications and functions. Multimerization and polymerization of proteins are some approaches for designing novel artificial enzymes with improved structures and functions (Albayrak and Swartz 2014; Yang et al. 2017). However, joining two or more units of protein to create polymeric proteins remains a challenge (Yu et al. 2015). Therefore, the preparation of multimeric and polymeric proteins requires careful consideration in the design of protein models and the strategy of multimerization or polymerization of proteins.

Artificial multimeric proteins are commonly prepared by genetic modification through tandem fusion or self-assembly through non-covalent bond formation (Pieters et al. 2016; Yin et al. 2018). However, the practical experiments for both methods differ. Tandem fusion engineers the protein at the gene level, while self-assembly engineers the protein at the protein level (Yu et al. 2015; Fan et al. 2018; Wang et al. 2018). Tandem fusion is a genetic modification technique commonly used in the design of multimeric proteins (Rizk et al. 2012; Bartels et al. 2019). The genes that encode the proteins of interest (POIs) are translated and expressed in the same expression cassette and joined mostly by adding rigid or flexible linkers (Rizk et al. 2012; Fan et al. 2018; Rullán-Lind et al. 2018). It does not involve the formation of covalent or noncovalent bonds. However, this strategy only works if the POI has similar characteristics, including chemical and physical properties; thus, protein fusion can be expressed by the host. Moreover, the fusion of proteins is limited to only a few units of proteins. Some unexpected results might occur in this strategy, such as misfolding, deactivation, and difficulties in protein expression and purification (Lan et al. 2015). In addition, tandem fusion only works for the preparation of multimeric proteins and cannot be applied to prepare protein-polymers, protein-DNA, and protein-nanoparticle (NP) conjugates (Domeradzka et al. 2016; Wang et al. 2018). Post-translational modifications (PTMs) are another common strategy that can be applied to the formation of multimeric and polymeric proteins; PTMs can appear at the $\mathrm{N}$ - or C-terminus or on the side chains of amino acids (Chou 2020). The genetically engineered proteins can undertake specific reactions of PTMs with some advantages such as wide options of catalyst, high yield of conjugates, and simple reaction. Therefore, PTMs are a suitable strategy for the multimerization and polymerization of proteins.

Figure 2 presents three common strategies for the preparation of multimeric or polymeric proteins. Crosslinking and self-assembly also involve genetic modifications in the design of protein models for the reaction. The modification of proteins by introducing specific peptide tags will be very useful for multimerization and polymerization reactions through selfassembly and crosslinking reactions. Therefore, the design of protein models is crucial for successful protein polymer formation.

\section{Protein multimerization through tandem fusion}

Advances in genomic and protein engineering have made the preparation of recombinant proteins easier and faster, while the development of new expression vectors and hosts for protein expression also supports advanced research and development in the preparation of multimeric and polymeric proteins. It is now possible to express multiple proteins by fusing genes encoding proteins in one expression cassette (Iturrate et al. 2010; Yu et al. 2015). However, the linker that connects proteins should be carefully considered and designed to avoid problems with protein expression (Yu et al. 2015). An interesting study on multimerization proteins through genetic modification was performed by the Yanhe Ma Laboratory which studied the formation of artificial fusion proteins and their application in methanol bioconversion (Fan et al. 2018). Three proteins from different sources, 3-hexulose-6-phosphate synthase (Hps), nicotinamide adenine dinucleotide (NAD)-dependent methanol dehydrogenase (Mdh), and 6-phospho-3-hexuloisomerase (Phi) from different sources were linked with two flexible linkers of different lengths: Gly-Gly-GlyGly-Ser (GGGS) ${ }_{3}$, and (GGGS) 6 (Fig. 3A). However, they found that the expression level of Hps-Phi-fused Mdh was lower than that of Mdh (Fig. 3B). This phenomenon was probably caused by the incompatibility between the fused proteins, which resulted in lower protein expression levels (Heck et al. 2013; Yu et al. 2015). This fusion strategy succeeded in improving the Mdh activity (Fig. 3C); however, the 
A
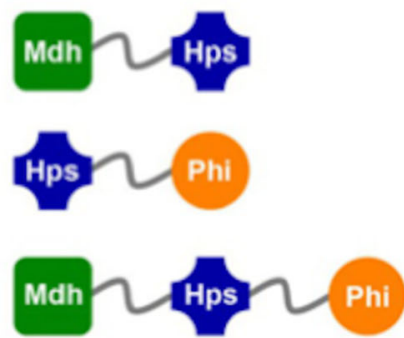

乙(GGGS) ${ }_{3}$ or (GGGGS)

C

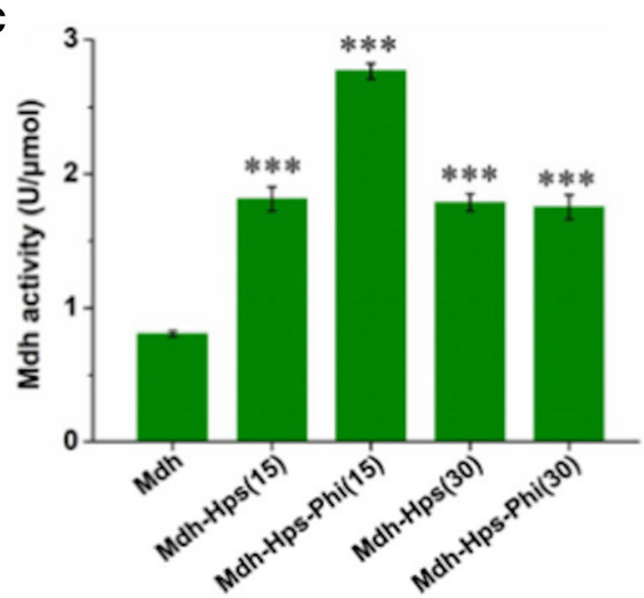

B
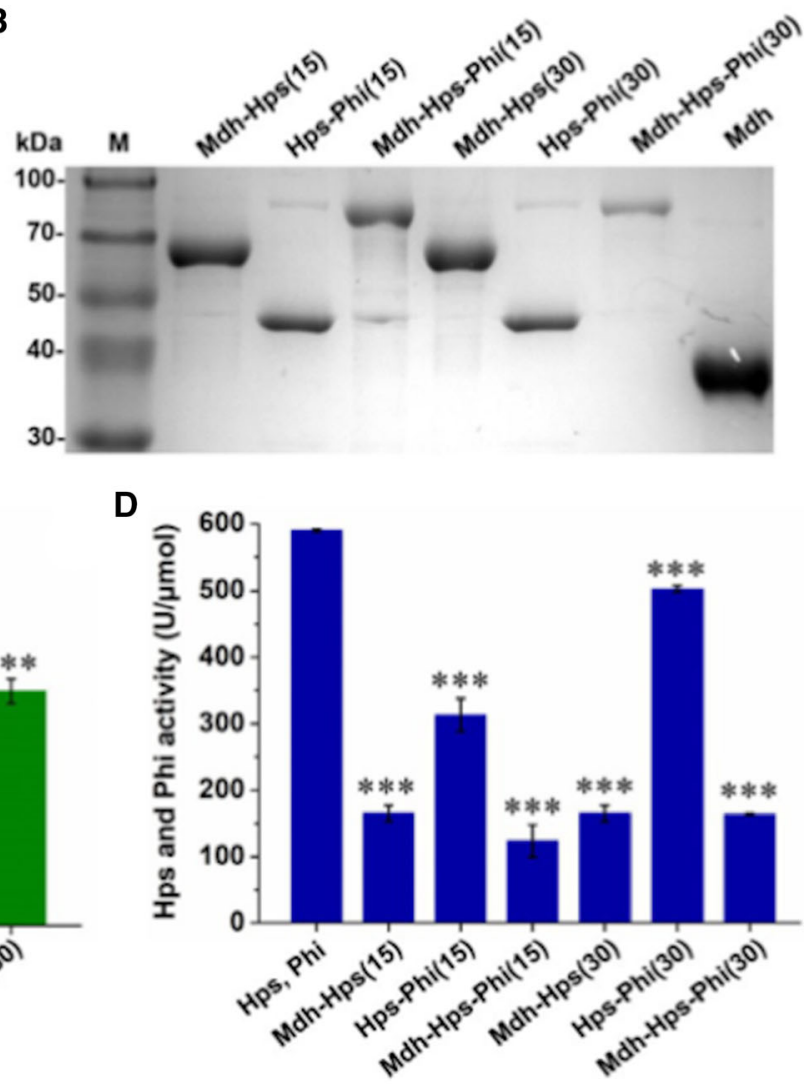

E

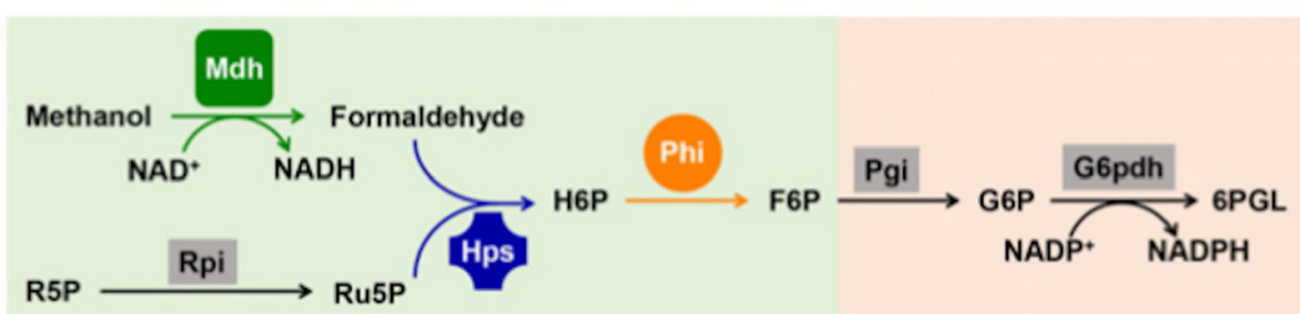

Formation phase

Detection phase

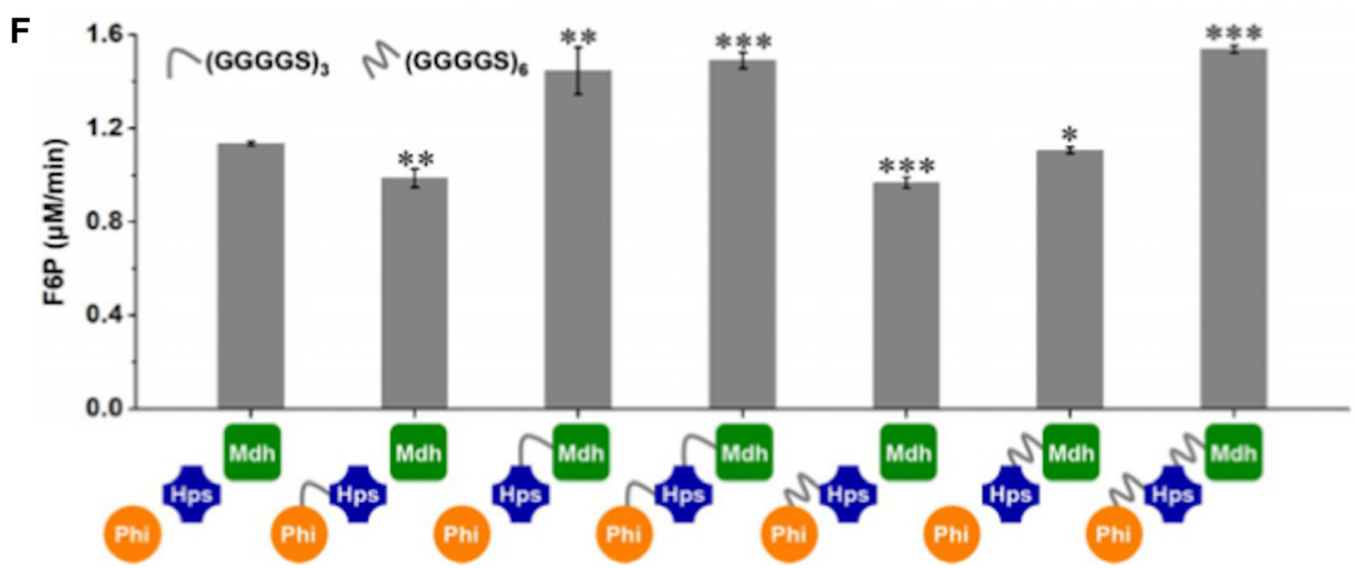


4Fig. 3 A Construction of fusion proteins that connect Mdh, $\mathrm{Hps}$, and Phi Two types of linkers of different lengths were used: 15 amino acids (GGGGS) 3 and 30 amino acids (GGGGS) ] $_{3}$. B SDS-PAGE analysis of proteins (fused and non-fused) after purification. The numbers in parentheses indicate the lengths of the linker(s). C, D Methanol oxidation activity of fused and free enzymes Hps and Phi activity of the fusion proteins (formation of NADPH and 6PGL from formaldehyde and R5P). E Schematic reaction of F6P formation and detection using fused and unfused enzymes. F Formation of F6P of the fused and free enzymes from methanol and R5P Reprinted from Fan et al. (2018). Copyright 2018 with permission from Wiley

activity of Hps and Phi of Mdh-fused Hps or Phi protein was lower than that of the control (Fig. 3D). The fusion of proteins likely negatively affects formaldehyde assimilation. Once again, the incompatibility of the proteins is responsible for this phenomenon. However, methanol conversion could be improved by fusing Mdh with Hps or Hps-Phi. The Vmax of methanol oxidation was 1.3-and 5.8-fold higher than that of non-fused Mdh, respectively (Fig. 3E-F) while the length of the linker (15 and 30 amino acids) only affected the Mdh and Hps-Phi activities of the fused proteins (Mdh-Hps-Phi and HpsPhi). To the best of our knowledge, fusion of these three proteins has the highest number of proteins to be fused. Therefore, the problem of protein expression and the effect of the linker on enzymatic activity could become a crucial problem in the preparation of multimeric proteins with a high number of protein units.

Protein polymerization through self-assembly reactions

The self-assembly of proteins is an applicable method for the preparation of multimeric proteins. Selfassembly of protein units to form protein polymers via non-covalent interactions offers some benefits such as catalyst-free, spontaneous, controlled, designed, and self-organizational reactions (Yin et al. 2018). Non-covalent interactions are mostly utilized to supervise the self-assembly of protein units, which offers the possibility of imitating the characteristics of native proteins. Non-covalent interactions, such as interprotein interactions, $\pi-\pi$ stacking, metalligand coordination, hydrophobic interactions, and host-guest interactions, are commonly applied to control the assembly by facilitating the connection of protein units (Janib et al. 2014; Yin et al. 2018). Therefore, self-assembly is a good option to create controlled and/or directed multimeric or polymeric protein assemblies.

Protein polymerization interactions display a remarkable degree of high specificity and affinity and can serve as a powerful force to induce proteinprotein recognition and aggregation. An impressive study was reported by Fegan et al. (2012), who designed and constructed chemically self-assembled antibody nanorings (CSANs) from dihydrofolate reductase (DHFR) fusion proteins (Fig. 4A). They used a newly synthesized chemical dimerizer, bismethotrexate (bisMTX-NH${ }_{2}$ ), which contains a linker that can be conjugated to drugs, radiolabels, and fluorophores. Interestingly, rapid internalization was conducted by assembling AntiCD3 CSANs with a fluorescein isothiocyanate (FITC)-labeled bismethotrexate ligand (bisMTX-FITC). The internalized bisMTX-FITC was trafficked by HPB-MLT, a CD3 + T-cell leukemia cell line, and was observed in the early and late stages of endosomes and lysosomes (Fegan et al. 2012). When incorporated into CSANs, the fluorescence of bisMTX-FITC was greater than that of the free ligand, and its stability could also be monitored. Interestingly, the internalized CSANs were also found to be stable for several hours. However, treatment with the nontoxic DHFR inhibitor trimethoprim resulted in a rapid loss $(>80 \%)$ of cellular fluorescence within minutes, consistent with efficient intracellular disassembly of the nanorings. Their reports suggest that cell receptor-targeting CSANs prepared with trifunctional bisMTX could be used as potential tissue-selective drug carriers (Fegan et al. 2012).

The next strategy for preparing protein polymers is to apply host-guest interactions as an approach to connect the protein units. Tu et al. (2011) reported an impressive and advanced design of monomers [CB[8]FGG pair and C2-symmetric homodimeric glutathione $S$-transferase (hdGST)] to create supramolecular protein polymers ( $\mathrm{Tu}$ et al. 2011). The CB[8]-FGG pair acts as an external inducer, while hdGST is the building block for genetic fusion with FGG peptides (Fig. 4B). The hdGSTs were connected by two phenyl groups assisted by $\mathrm{CB}[8]$. As a result, the molecular size and weight of the polymeric protein chains were dramatically increased owing to the end-to-end 
A

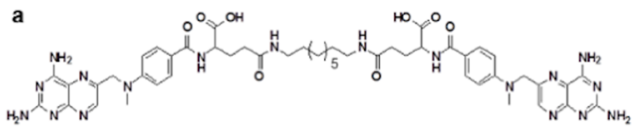

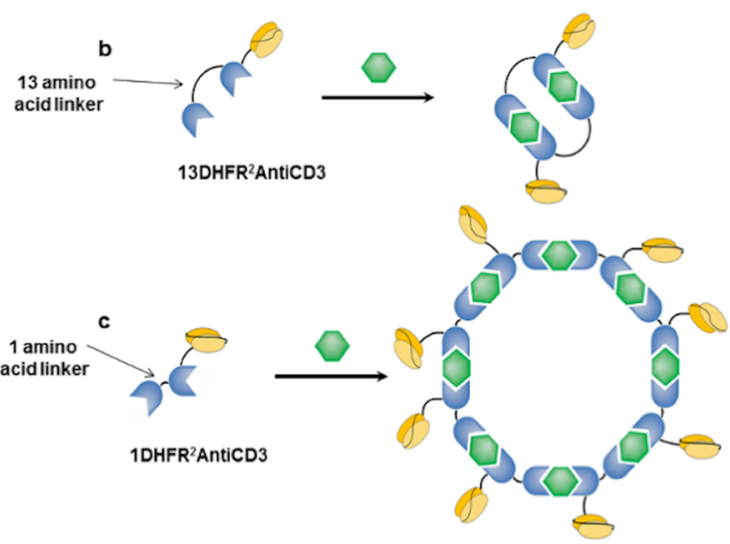

C
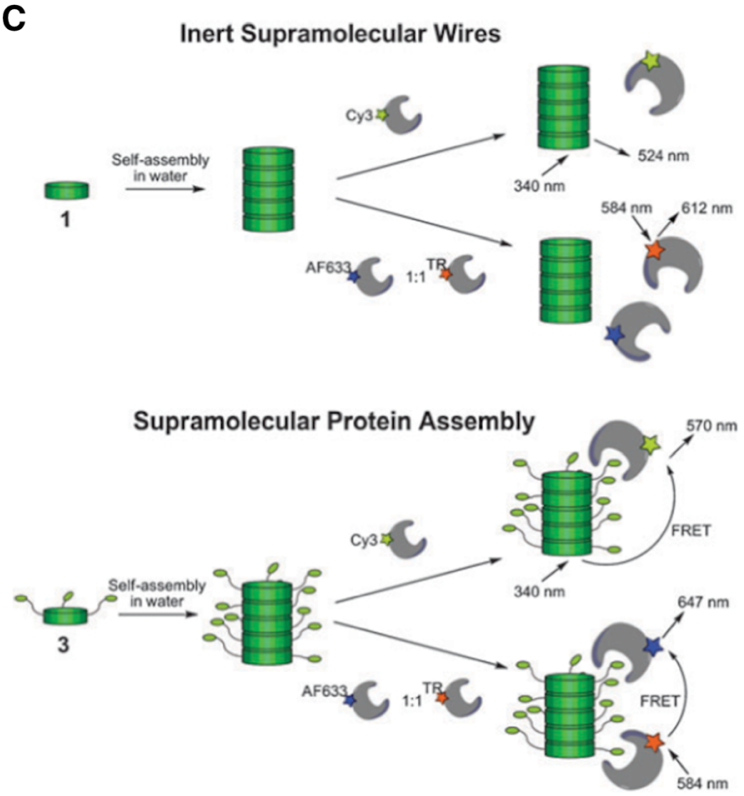

Fig. 4 Supramolecular protein polymerization is formed by different interactions between the protein units. A Protein polymerization induced by interprotein interactions. The blue color is DHFR, yellow color is antiCD3 in yellow, and green color is bisMTX. Reprinted from (Fegan et al. (2012) Copyright 2018 with permission from the American Chemical Society (ACS). B Protein polymerization via host-guest interactions. Reprinted from Tu et al. (2011) Copyright 2011 with permission
B
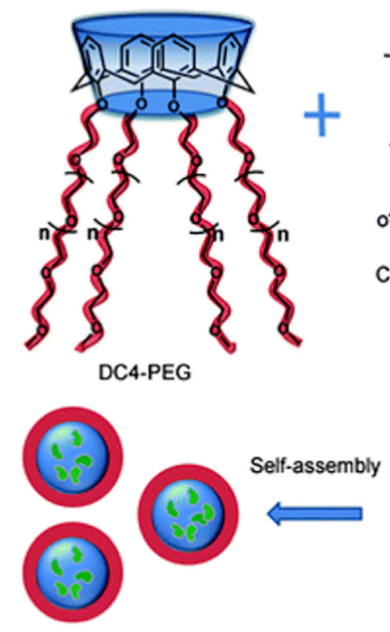

Supramolecular Polymeric Micelles

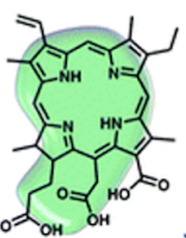

Chlorin e6 (Ce6)
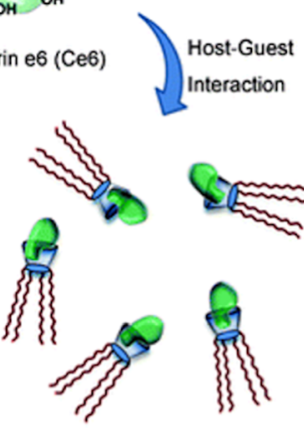

Host-Guest complex

\section{D}

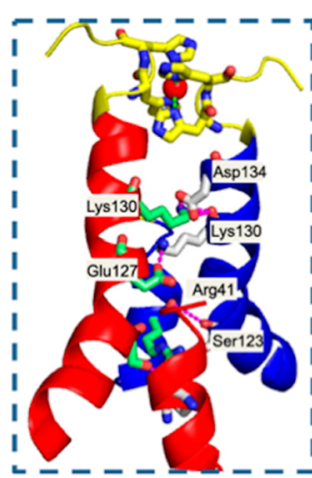

sjGST-2His Dimer
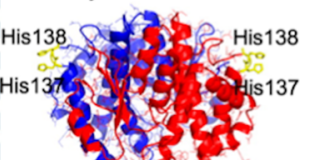

-
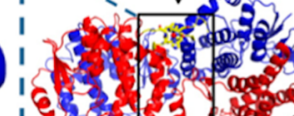

-
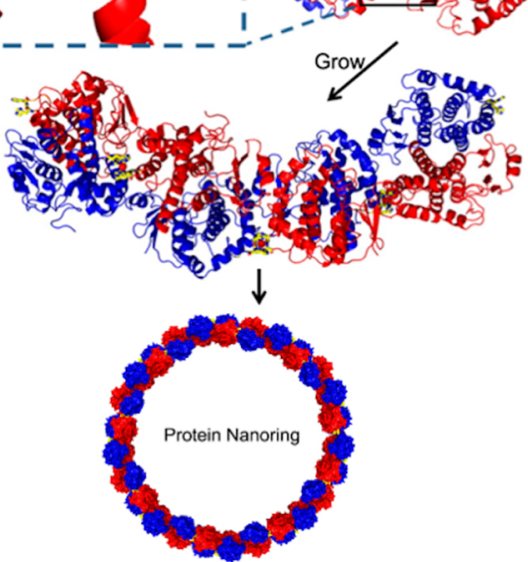

from the Royal Society of Chemistry (RSC). C Protein polymerization is directed by aromatic $\pi-\pi$ stacking. Reprinted from Müller et al. (2011) Copyright 2011 with permission from the Royal Society of Chemistry (RSC). D Metal-coordinationdriven polymerization of proteins. Reprinted from Bai et al. (2013). Copyright 2013 with permission from the American Chemical Society (ACS) 
interconnection of hdGSTs. Fortunately, the stability of hdGST assemblies makes them easier to separate by size exclusion chromatography (SEC). Moreover, it can be easily functionalized with glutathione peroxidase (GPx)-like catalytic centers using a cysteine auxotrophic expression system. More importantly, the hdGST assemblies have excellent antioxidant properties, which may find useful applications in catalysis, biosensors, and pharmaceuticals.

Another two strategies for preparing supramolecular polymeric proteins through self-assembly are $\pi-\pi$ stacking (Fig. 4C) and metal-ligand coordination (Fig. 4D). Müller et al. (2011) designed an autofluorescent supramolecular polymer that can be used as a platform for protein assembly. The discotic monomers were designed as assembly agents to reversibly form a columnar polymer (molecule 1). Interestingly, a columnar polymer was formed in water, even at low monomer concentrations. By providing this self-assembled molecular wire with ligands (molecule 3), they utilized it to assemble proteins. This design and strategy provide attractive architectures for protein assembly and, thus, novel shapes could be achieved, such as columnar wires, on which proteins can be made to aggregate and interact (Müller et al. 2011). Finally, Bai et al. (2013) demonstrated an impressive strategy for constructing self-assembled protein nanorings by utilizing Schistosoma japonicum glutathione S-transferase (sjGST) as the building block (Bai et al. 2013). This is a very stable and homodimer containing two subunits noncovalently connected to each other and related by a two-fold axis (C2 symmetry). It also has two properly oriented His metal-chelating sites on the surface, which can be utilized as sites for synergic metalcoordination and non-covalent interactions to create nanorings through metal-ligand coordination (Fig. 4D). However, designing the chelating sites of sjGST is challenging. These are three key factors to be considered: (1) the chelating sites overhang from the sjGST surface. (2) The chelating site shape should have a proper orientation to maintain a ' $\mathrm{V}$ ' shape. (3) Finally, the distance of the bishistidine (bis-His) clamp was placed appropriately. The mutation of Cys137 mutation into a His residue would result in a perfect bis-His metal-binding site and form a dimer variant that could fulfill the above three requirements. As a result, sjGST is bound together and is site-specifically driven by metal ion $\left(\mathrm{Ni}^{+}\right)$coordination. Moreover, the interfaces were "pulled" tightly by non-covalent interactions between $\mathrm{Ni}^{+}$and chelating site of sjGST to form a very stable structure which was controlled thermodynamically. The assembly then started to demonstrate a flexible trend and ultimately grew into a nanoring. This strategy can be used to create an accurate protein polymer with high dimensions and sophisticated configurations.

\section{Protein polymerization through crosslinking reactions}

The crosslinking reaction of proteins is described as the reaction of joining two or more proteins through covalent bonds. The newly formed covalent bonds between protein units can be catalyzed by chemicals (Campbell et al. 1998; Smith et al. 2010; Gunnoo and Madder 2016), enzymes (Stephanopoulos and Francis 2011; Heck et al. 2014; Minamihata et al. 2016), chemoenzymatic (Rabuka 2010; Díaz-Rodríguez and Davis 2011), metals (Wedrychowski et al. 1986; Albayrak and Swartz 2014), and light (Kim et al. 1999). The crosslinking reaction can be performed via in vivo and in vitro reactions and can target some natural amino acids (NAA) for modification sites or points. However, not all amino acids are accessible because of their location and abundance on the surface of proteins. Some natural amino acids, such as serine, glutamine, glutamic acid, glycine, lysine, and aspartic acid, are located on the surface of proteins (Jung and Theato 2013). They also have a high value of average surface accessibility (ASA) (Table 1), which means that they can be recognized and reacted with the catalyst in the crosslinking reaction. Another amino acid can also be targeted as a modification site; however, further modifications are required (Jung and Theato 2013). Some researchers have also applied non-natural amino acids (NNAAs) for crosslinking reactions or specific labeling of proteins. However, engineering a protein with NNAAs requires careful consideration because it cannot be recognized by most enzymes. Further chemical reactions are required to modify or cross-link NNAAs of proteins. Thus, protein crosslinking through the existing NAA is preferable for most researchers. 
Table 1 The amino acids used as a target in protein crosslinking reaction: amino acid, location, functionality, natural abundance, and their average surface accessibility
${ }^{a}$ Location of amino acids in the core $(\mathrm{C})$, intermediate (M), and surface (S)

${ }^{\mathrm{b}}$ Average surface accessibility

Reproduced from Jung and Theato (2013). Copyright 2011 with permission from Springer Nature

\begin{tabular}{|c|c|c|c|c|}
\hline Amino acid & Location $^{\mathrm{a}}$ & Functionality $^{\mathrm{b}}$ & Natural abundance & $\mathrm{ASA}^{\mathrm{b}}$ \\
\hline Cysteine & $\mathrm{C}$ & Thiol & 1.36 & 0.268 \\
\hline Isoleucine & $\mathrm{C}$ & Aliphatic & 5.97 & 0.273 \\
\hline Tryptophan & $\mathrm{C}$ & Indole & 1.08 & 0.279 \\
\hline Phenylalanine & $\mathrm{C}$ & Benzyl & 3.86 & 0.290 \\
\hline Valine & $\mathrm{C}$ & Aliphatic & 6.87 & 0.306 \\
\hline Tyrosine & $\mathrm{C}$ & Phenol & 2.92 & 0.319 \\
\hline Leucine & $\mathrm{C}$ & Aliphatic & 9.66 & 0.321 \\
\hline Methionine & $\mathrm{C}$ & Thioether & 2.42 & 0.364 \\
\hline Alanine & $\mathrm{C}$ & Aliphatic & 8.26 & 0.405 \\
\hline Histidine & M & Imidazole & 2.27 & 0.425 \\
\hline Threonine & M & Hydroxy & 5.34 & 0.480 \\
\hline Proline & M & Aliphatic & 4.69 & 0.502 \\
\hline Arginine & M & Guanidine & 5.53 & 0.539 \\
\hline Asparagine & M & Carboxamide & 4.06 & 0.568 \\
\hline Serine & $\mathrm{S}$ & Hydroxy & 6.55 & 0.568 \\
\hline Glutamine & $\mathrm{S}$ & Carboxamide & 3.93 & 0.573 \\
\hline Glutamic Acid & $\mathrm{S}$ & Carboxylic acid & 6.75 & 0.586 \\
\hline Glycine & $\mathrm{S}$ & - & 7.08 & 0.588 \\
\hline Lysine & $\mathrm{S}$ & Primary amine & 5.85 & 0.607 \\
\hline Aspartic Acid & $\mathrm{S}$ & Carboxylic acid & 5.46 & 0.615 \\
\hline
\end{tabular}

Protein polymerization through chemical crosslinking reaction

The crosslinking reaction of proteins can be accomplished by a massive variety of chemicals as crosslinkers with distinct properties and aims for different reactive groups on the proteins (Stephanopoulos and Francis 2011). The selective modification of proteins by using chemicals is possible and successful for reactions that use engineered proteins, for example, the engineered protein with site-directed mutagenesis or specific labeled-proteins. Some amino acids are exposed to the surface of proteins, which makes it easier for them to react with chemical agents. The most commonly used reactive groups are $-\mathrm{NH}_{2}$ (Leitner et al. 2014; Falatach et al. 2015; Hoffman et al. 2015; Onoda et al. 2020), -SH (Masri and Friedman 1988; Smith et al. 2010), aryl-OH (Kim et al. 1999; Joshi et al. 2004; Viljanen et al. 2004), and - $\mathrm{COOH}$ (Pei et al. 2010; Falatach et al. 2015). Although other reactive amino acid groups have lower ASA values, it is still possible to become a target of the crosslinking reaction. Small chemical molecules can avoid the steric hindrance of proteins and react with the hidden amino acids. Most of the chemical reactions involved in protein crosslinking reactions are substitution, oxidation, and addition reactions. Consequently, the substitution and addition reactions involve leaving groups, which vary based on the chemicals used. Moreover, the activation of nucleophiles is essential for initiating the reaction with such activation requiring a catalyst, a specific solvent, and temperature. This means the chemical crosslinking takes more time than enzymatic crosslinking, which can proceed within minutes.

Although chemical crosslinking offers many catalyst options, as far as we aware there are only a few chemical agents which can be used for protein polymerization reaction, such as glutaraldehyde (Silva et al. 2004; Roy and Abraham 2006) and formaldehyde (Jackson 1999; Hoffman et al. 2015). Most chemical agents are effective catalysts for protein labeling and the formation of protein conjugates. The protein polymerization reaction requires a strong oxidant to form free radicals, which initiates the polymerization reaction. Enzymes are better alternatives to chemical agents in most chemical reactions, including the crosslinking reaction of proteins. The site-specificity reaction is the most interesting feature of enzymes involved in the crosslinking reaction of 
proteins as the enzymes will only recognize and react with a specific residue or sequence of proteins, which is very useful in the design of protein targets. Although the enzyme options for the crosslinking reaction of proteins are not as effective as chemical agents, it is not a limitation to apply it as a catalyst.

Protein polymerization through enzymatic crosslinking reaction

Enzymatic crosslinking reactions for protein modification or functionalization have attracted the attention of researchers owing to the high site-specificity of the reaction. Enzymes are powerful catalysts for the crosslinking of proteins if they react with genetically modified target proteins that harbor specific peptides or sequence tags (Minamihata et al. 2011; Heck et al. 2013). Reactive and specific peptides or sequence tags play essential roles in the enzymatic crosslinking of proteins, such as those catalyzed by horseradish peroxidase (HRP) (Minamihata et al. 2012; Roberts et al. 2016), laccase (Permana et al. 2019, 2020), lysil oxidase (Moreira Teixeira et al. 2012), transglutaminase (Kamiya et al. 2003; Mori et al. 2011), lipoic acid ligase (Hauke et al. 2014), biotin ligase (Granhøj et al. 2019), bacterial sortase (Heck et al. 2014), and phosphopantetheinyl transferase (PFTase) (Rabuka 2010) which require additional peptides or sequence tags for successful site-specific crosslinking reactions.

Most enzyme options for the crosslinking reaction of proteins are effective only for protein conjugate formation and protein labeling with specific molecules (Table 2). However, they cannot be employed for protein polymerization because of the limitations of the reaction. For example, they cannot undergo oxidation reactions on the substrates to form reactive free radicals, which are required for the non-enzymatic polymerization of proteins. There are some enzymes from the oxidoreductases (EC 1) family that can oxidize substrates to form free radicals, and the crosslinking between free radicals occurs non-enzymatically without the formation of tripartite complexes, which are required for other enzymes. Transglutaminases, a member of transferases (EC 2), can also be used as catalysts in the polymerization reaction of proteins. However, a specific design of the protein model is required. Therefore, the design of protein targets and correct enzymes is a crucial step in protein polymerization.
Transglutaminase

Transglutaminases (TGs, EC 2.3.2.13) are one of the most comprehensively studied transferases (EC 2) for site-specific crosslinking reactions of proteins. Some TGs are calcium-dependent enzymes, acyltransferases that catalyze the transfer reaction of a $\gamma$-carboxyamine group of glutamine $(\mathrm{Q})$ to the $\varepsilon$-amine group of lysine (K) to form cross-linked proteins (Buchert et al. 2010). TGs isolated from Streptomyces mobaraensis (microbial TGs or MTG) are powerful catalysts for preparing protein conjugates, including protein-proteins (Mori et al. 2013), protein-nanoparticles (Janib et al. 2014; Chen et al. 2015), protein-polymers (Wakabayashi et al. 2017), protein-lipids (Takahara and Kamiya 2019), and protein-nucleotide conjugates (Kitaoka et al. 2012).

An interesting study on the MTG-catalyzed polymerization reaction was reported by Sato et al. (2020) at the Kamiya Laboratory. They prepared GFP mutants with unique MTG-recognizable peptide tags to form scaffold-less functional protein assemblies. They designed two peptide tags: double tag at N- and C-terminus (Fig. 5A) and newly proposed 'PolyTag' which promotes intermolecular crosslinking of proteins by introducing the lysine and glutamine residues in StrepTag I (Fig. 5B). This PolyTag successfully assisted MTG in the polymerization of the EGFPStrepTag I monomer and avoided intramolecular cyclization (Fig. 5C) (Sato et al. 2020). In contrast, circular EGFPs were formed from the polymerization reaction of KTag-EGFP-StrepTag I due to covalent bond formation between the Q-tag and K-tag (Fig. 5D). They further confirmed that heteromeric protein assemblies could also be formed by mixing polytagged proteins. The BRET analysis results of heteromeric assemblies comprising EGFP and Nanoluc showed that these proteins were stable in their assembled form. The results obtained also suggest that the arrangement of PolyTag and MTG provides a promising molecular tool for designing scaffold-less protein assemblies (Sato et al. 2020).

Tyrosinases

Tyrosinase (EC 1.14.18.1) is a copper-containing enzyme that catalyzes the four-electron oxidation of tyrosine residues to o-quinones; it is an oxygendependent enzyme. The formed quinones can easily 
Table 2 List of enzymes that used as catalyst in crosslinking reaction

\begin{tabular}{|c|c|c|}
\hline $\begin{array}{l}\text { Recognition site or } \\
\text { sequence }\end{array}$ & $\begin{array}{l}\text { Target of amino } \\
\text { acids }\end{array}$ & Enzymes \\
\hline$-\left\{-\mathrm{NH}_{2}\right.$ & $\begin{array}{l}\text { N-terminus } \\
\varepsilon \text {-amino group } \\
\text { of lysine }\end{array}$ & $\begin{array}{l}\text { Transglutaminases (Tominaga et al. 2007; Sato et al. 2020), Lysil oxidases (Moreira } \\
\text { Teixeira et al. 2012) }\end{array}$ \\
\hline $\begin{array}{l}-\xi-\text { SH } \\
\text { Thiol }\end{array}$ & Cysteine & $\begin{array}{l}\text { Laccases (Mattinen et al. 2006), peroxidases (Milczek 2018), protein farnesyltransferases } \\
\text { (PFTase) (Zhang et al. 2019) }\end{array}$ \\
\hline\{ & Tyrosine & $\begin{array}{l}\text { Peroxidases (Minamihata et al. 2011, 2016; Jia et al. 2017), tyrosinases (Jus et al. 2008; } \\
\text { Faccio et al. 2014), laccases (Hollmann and Arends 2012; Permana et al. 2020) }\end{array}$ \\
\hline CXPXR & Cysteine & Formylglycine-generating enzyme (FGE, EC 1.8.3) (Roeser et al. 2006) \\
\hline CAAX & Cysteine & Protein farnesyltransferase (PFTase, EC 2.5.1.58) (Zhang et al. 2019) \\
\hline DSLEFIASKLA & Serine & Phosphopantetheinyl transferase (PPTase, EC 2.7.8.7) (Rabuka 2010) \\
\hline T/SXXXG & $\begin{array}{l}N \text {-terminal } \\
\text { glycine }\end{array}$ & $N$-myristoyltransferase (NMT, EC 2.3.1.97) (Heal et al. 2002) \\
\hline GFEIDKVWYDLDA & Lysine & Lipoate-protein ligase A (LplA, EC 6.3.1.20) (Hauke et al. 2014) \\
\hline LPXTG & Glycine & Sortase A (SrtA, EC 3.4.22.70) (Heck et al. 2014; Garg et al. 2018) \\
\hline GLNDIEAQKIEWHE & Lysine & Biotin-[acetyl-CoA-carboxylase] ligase (BirA, EC 6.3.4.15) (Granhøj et al. 2019) \\
\hline
\end{tabular}

cross-link with cysteinyl, lysyl, or tyrosyl residues (Selinheimo et al. 2007) Tyrosinase-catalyzed crosslinking of proteins is an appealing transformation for pharmaceutical or food companies because it produces water as the sole product. Tyrosinase has been used as a catalyst for many protein crosslinking reactions to prepare protein conjugates or protein polymers (Lobba et al. 2020; Mogilevsky et al. 2021). However, only a few reports have studied the tyrosinase-catalyzed, non-site-specific polymerization reaction of proteins including $\alpha$-casein (Selinheimo et al. 2008), $\beta$-casein (Mattinen et al. 2008), collagen (Jus et al. 2011), and rutin (quercetin-3-rutinoside) (Desentis-Mendoza et al. 2006). Some mediators, commonly phenolic acids, are required for tyrosinase-catalyzed polymerization reactions (Selinheimo et al. 2008). The mechanism of the reaction of tyrosinases in protein oxidation is different from that of peroxidases and laccases, which involve the formation of a very reactive species, free tyrosyl radicals. Tyrosinases catalyze the formation of quinones, including dopaquinone and indole-5,6-quinone (Mattinen et al. 2008) and these can help the formation of protein conjugates and polymers with two different products, aldol and Schiff-base products (Milczek 2018).

\section{Peroxidases}

Peroxidases (EC 1.11.1.7) are the most commonly used oxidoreductases in the polymerization of proteins and can catalyze the oxidation reaction of phenolic moieties of tyrosine residues to form free tyrosyl radicals, making it an applicable enzyme for many protein polymerization reactions. Peroxidases typically react with tyrosine, lysine, and cysteine, resulting in heterogeneous products (Milczek 2018). However, tyrosine residues are preferable for reactions with peroxidases. Further protein modifications are required for site-specific crosslinking of proteins catalyzed by peroxidases. For example, tyrosine residues should be exposed on the surface of proteins and can be recognized by peroxidases (Minamihata et al. 2012, 2015). Horseradish peroxidase (HRP) is the most frequently used peroxidase in protein polymerization reactions and has been used to polymerize bacterial alkaline phosphatase (BAP) (Minamihata et al. 2011, 2012), protein $\mathrm{G}(\mathrm{pG})$ (Minamihata et al. 2016), chimeric antibody binding protein (ABP) (Minamihata et al. 2015), and SpyCatcher (Jia et al. 2017). Minamihata et al. (2011) modified an Escherichia coli alkaline phosphatase (BAP) by adding a 
A

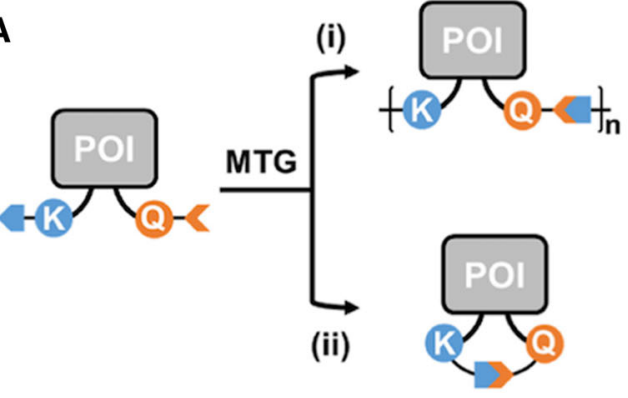

C

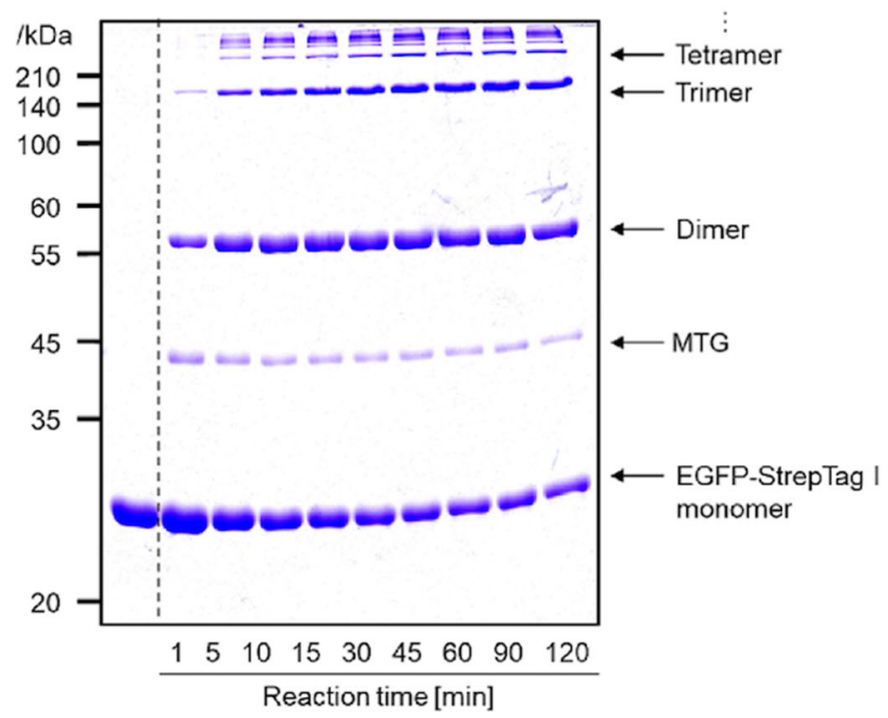

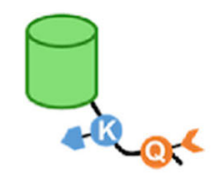

EGFP-StrepTag | monomer

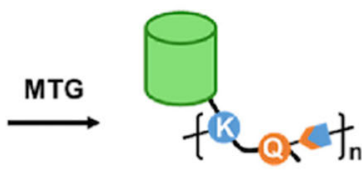

EGFP-StrepTag I assembly
Fig. 5 Strategy and POI design for the MTG-catalyzed polymerization reaction. A Introduction of a mono-reactive peptide tag (K- or Q-tag) to each terminus (N- and C-termini) of POIs, which hints to (i) polymerization or (ii) self-cyclization reaction. B Introduction of a peptide tag containing lysine (K) and glutamine (Q) residues (StrepTag I) to the POI for

Y-tagged and flexible linker at the $\mathrm{C}$-terminus, which can be recognized by HRP. The Y-tagged BAPs showed great reactivity against HRP and formed branched polymeric BAPs. However, they found that the enzymatic activity of HRP-treated BAP decreased slightly after the reaction. $\mathrm{H}_{2} \mathrm{O}_{2}$, which is required as an electron acceptor, and is a significant problem for peroxidases. The additional $\mathrm{H}_{2} \mathrm{O}_{2}$ could be responsible
B

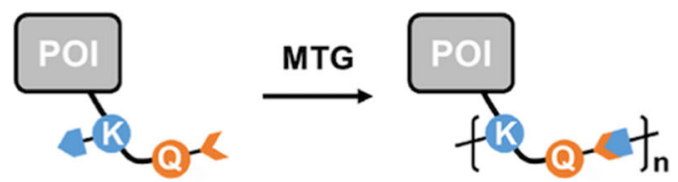

D
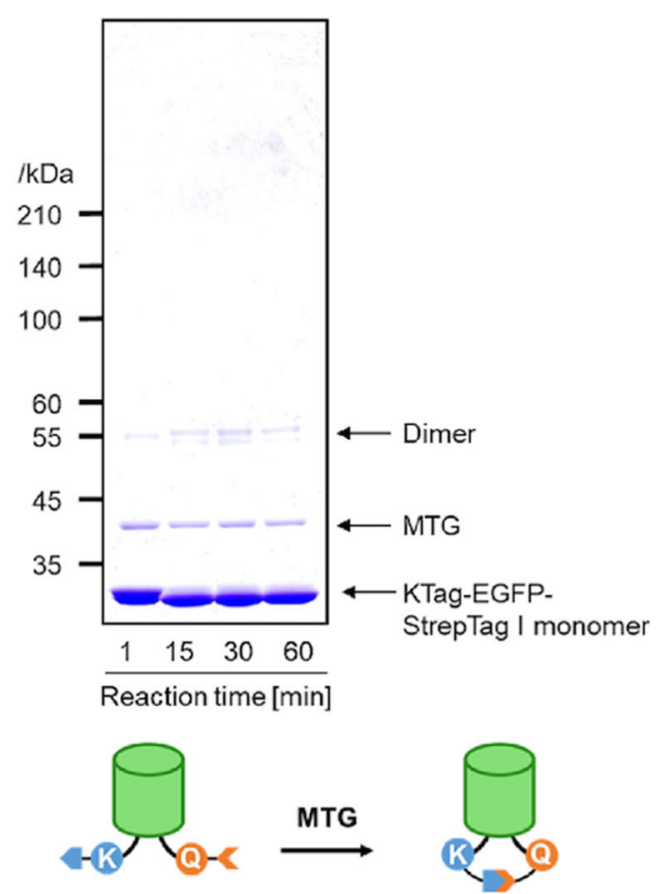

KTag-EGFP-StrepTag I monomer scaffold-less protein assembly. C SDS-PAGE analysis of the MTG-catalyzed polymerization reaction of EGFP-StrepTagI against incubation time. D SDS-PAGE analysis of the MTGcatalyzed polymerization reaction of KTag-EGFP-StrepTagI against incubation time. Reprinted from Sato et al. (2020). Copyright 2020 with permission from Elsevier

for the changes in the activity of the BAPs. Another possibility is that the large and branched polymeric structures of BAPs may affect their enzymatic activity. An extra amount of $\mathrm{H}_{2} \mathrm{O}_{2}$ is harmful and unacceptable for food and pharmaceutical products.

An impressive study of the HRP- and MTGcatalyzed formation of polymeric chitinase was reported by Minamihata et al. (2021) who engineered 
a chitinase from $P$. ryukuensis (ChiA) by removing the chitin binding domain ( $\left.\mathrm{LysM}_{2}\right)$ and modifying the catalytic domain (CatD) of chitinase by adding Y-and $\mathrm{KY}$-tags at the $\mathrm{N}$-and $\mathrm{C}$-termini of CatD, respectively. They also engineered the wild-type ChiA by adding Y-and KY-tags, similar to the CatD, to construct Y-ChiA-KY and used it as a control. Y- and KYtagged ChiA and CatD were used as protein models in an HRP-catalyzed polymerization reaction. Polymerization of Y-ChiA-KY did not significantly improve the antifungal activity of ChiA. It is possible that the complex structure of ChiA and its $\mathrm{LysM}_{2}$ in the Y-ChiA-KY polymers caused a saturated structure and inhibited its antifungal activity. In contrast, the removal of $\mathrm{LysM}_{2}$ from $\mathrm{ChiA}$ to construct the Y-CatD-KY and Y-CatD-KY polymers resulted in the loss of antifungal activity against Trichoderma viride. This suggests that the absence of $\mathrm{LysM}_{2}$ caused the loss of capability of CatD to bind to the chitin region of the fungi. To improve the antifungal activity of CatD, the authors proposed two strategies for polymerization of Y-CatD-KY: (i) direct copolymerization of Y-CatD-KY and Y-LysM ${ }_{2}-\mathrm{KY}$ with different molar ratios of Y-CatD-KY to Y-LysM ${ }_{2}-\mathrm{KY}$ catalyzed by HRP (Fig. 6A). (ii) Polymerization of Y-CatD-KY catalyzed by HRP was followed by grafting of $\mathrm{LysM}_{2}-\mathrm{Q}$ to $\mathrm{Y}-\mathrm{CatD}-\mathrm{KY}$ polymers catalyzed by microbial transglutaminase (MTG). The SDS-PAGE results of CatD/LysM ${ }_{2}$ copolymers (prepared by direct copolymerization) (Fig. 6B) and $\mathrm{LysM}_{2} \mathrm{G} / \mathrm{CatD}$ polymers (prepared by polymerization and grafting reaction) (Fig. 6C) suggested that both strategies could be used to prepare polymeric Y-CatDKY. Although the activity of both polymers was not as high as that of the control (WT-ChiA) against glycol chitin as a soluble substrate (Fig. 6D) and against chitin powder as an insoluble substrate (Fig. 6E), they exhibited antifungal activity against $T$. viride. As expected, CatD/LysM $\mathrm{L}_{2}$ copolymers showed lower activity than WT-ChiA (Fig. 6F). Again, the bulky structure of the polymer and random $\mathrm{LysM}_{2}$ position may contribute to its lower antifungal activity. In contrast, the $\mathrm{LysM}_{2} \mathrm{G} / \mathrm{CatD}$ polymers showed higher antifungal activity than the WT-ChiA and CatD/ $\mathrm{LysM}_{2}$ copolymers. The correct distribution of $\mathrm{LysM}_{2}$ on its structure may play a significant role in its antifungal activity. This suggests that ChiA and CatD only require a low number of $\mathrm{LysM}_{2}$ on its structure to hydrolyze the chitin walls of $T$. viride. This study is quite interesting and could contribute to the further development of functional protein polymers, in which the ratio of the protein components and their 3D arrangements are critical for their functionality.

\section{Laccases}

Laccases (EC 1.10.3.2) are multi-copper-binding enzymes primarily employed in the textile and pulp industries as catalysts for aromatic polymer degradation. Laccases, similar to peroxidases, catalyze the oxidation of phenolic compounds using molecular oxygen, resulting in the formation of free radicals and water. The newly formed free radicals can undergo radical reactions, such as polymerization, hydration, disproportionation, and fragmentation. Laccase-catalyzed crosslinking reactions commonly produce heterogeneous products, guiding dityrosine and isodityrosine formation, or a higher degree of tyrosine coupling and disulfide intermolecular bonds of proteins. Laccases have been used to polymerize bacterial alkaline phosphatase (BAP) (Permana et al. 2018, 2020), silkworm-expressed HRP (Permana et al. 2019), chimeric antibody-binding protein (ABP) (Permana et al. 2018, 2020), $\alpha$-casein (Selinheimo et al. 2008), $\beta$-casein (Mattinen et al. 2008), collagen (Jus et al. 2011), coactosin (Mattinen et al. 2006), and whey protein isolate (WPI) (Ma et al. 2011). Laccases are good candidates that can become an alternative or even substitute for HRP in the preparation of protein polymers. Laccase provides the same site-specificity as HRP and one of their advantages is that they only use molecular oxygen as the terminal oxidant for the oxidation of phenolic compounds. According to the site-specificity of laccases against tyrosine, tyrosine-modified proteins are good substrates for laccases.

Permana et al. (2020) presented an interesting report on the use of laccase in the polymerization reaction in which they polymerized a bacterial alkaline phosphatase (BAP) from Escherichia coli using a laccase from Trametes sp. (TL). To substitute the use and function of phenolic mediators in the laccase-catalyzed crosslinking reaction of proteins, they engineered the dimeric BAP by inserting a tyrosine-containing loop protein (Y-Loop) into the loop domain of the BAP structure at the position 219-221 of amino acid to construct BAP-Loop-Y (Fig. 7A) (Permana et al. 2020). Y-Loop consists of 
A
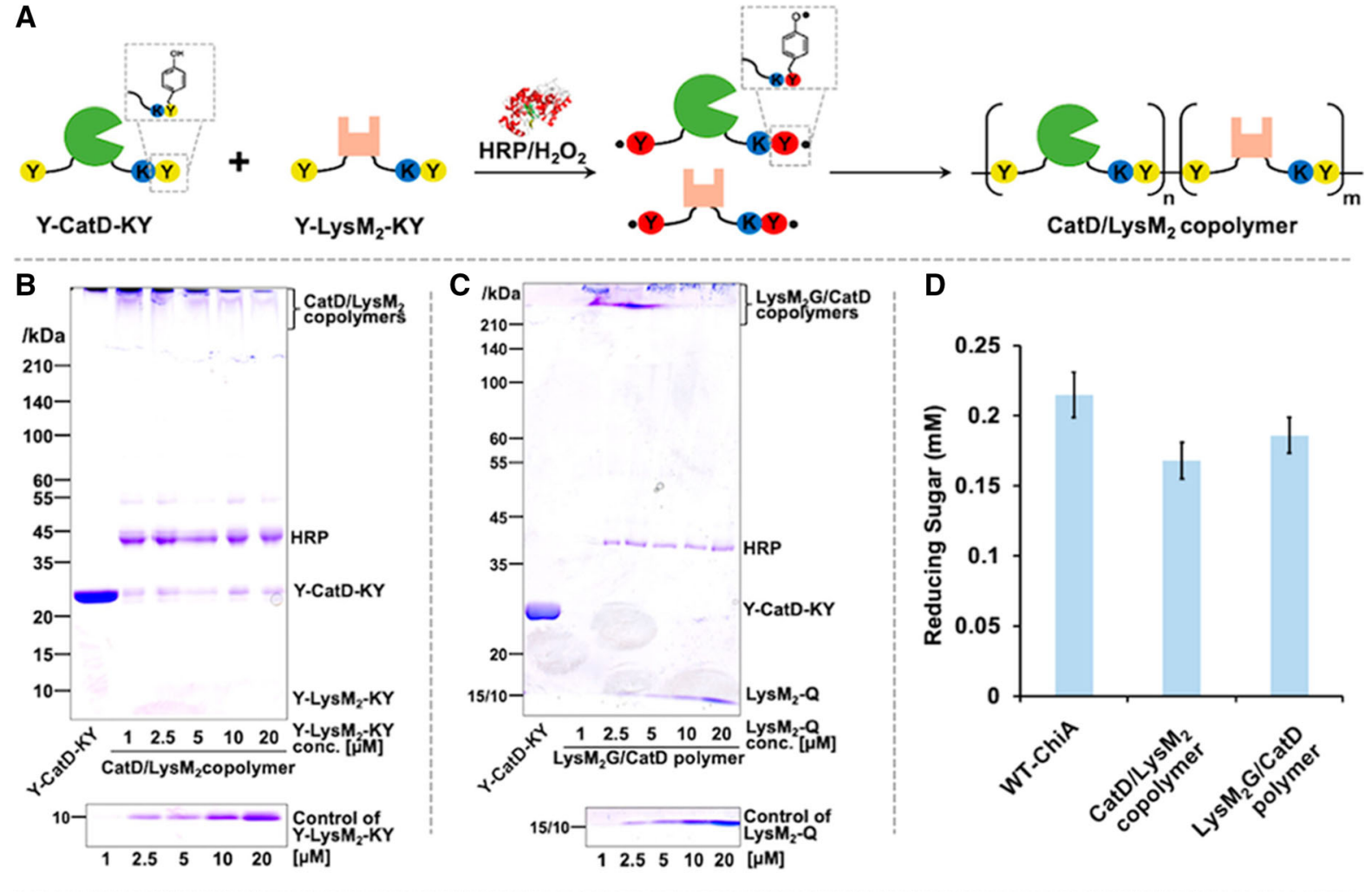

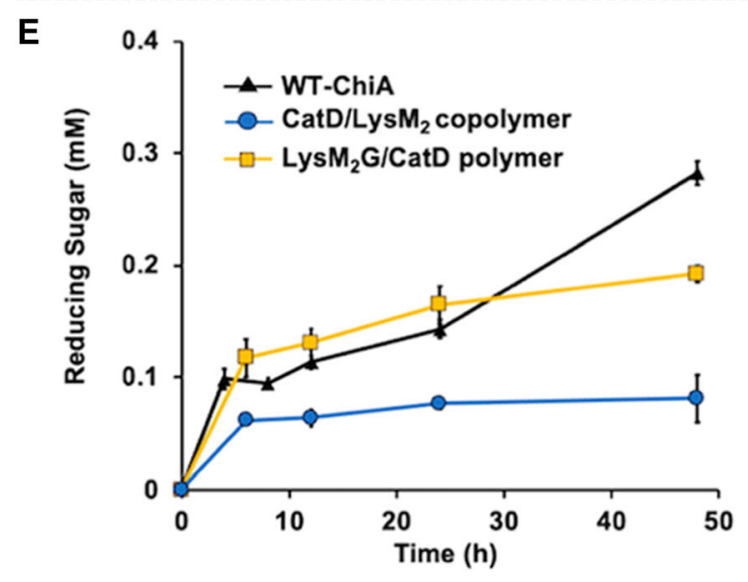

Fig. 6 A The schematic strategy for the HRP-catalyzed random copolymerization of Y-CatD-KY and Y-LysM $\mathrm{L}_{2}-\mathrm{KY}$ to form CatD/LysM ${ }_{2}$ copolymers, B SDS-PAGE analysis of the HRPcatalyzed copolymerization of Y-CatD-KY and Y-LysM ${ }_{2}-\mathrm{KY}$ with varying concentrations of Y-LysM $\mathrm{L}_{2}-\mathrm{KY}, \mathrm{C}$ HRP- and MTG-mediated grafting of $\mathrm{LysM}_{2}-\mathrm{Q}$ onto the CatD polymer with varying concentrations of $\mathrm{LysM}_{2}-\mathrm{Q}$. D The enzymatic activity of WT-ChiA, CatD/LysM 2 copolymers, and $\mathrm{LysM}_{2} \mathrm{G}$ / CatD polymers against glycol chitin as a soluble substrate.

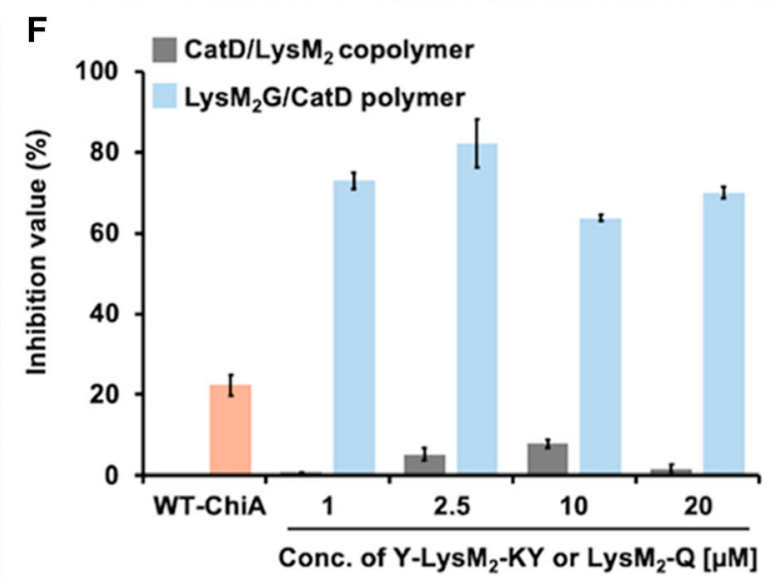

E The enzymatic activity of WT-ChiA, CatD/LysM $\mathrm{M}_{2}$ copolymer, and $\mathrm{LysM}_{2} \mathrm{G} / \mathrm{CatD}$ polymer against chitin powder as an insoluble substrate. The substrate concentration was $0.5 \%$ (wt\%). F Results of inhibition assay of WT- ChiA, CatD/ $\mathrm{LysM}_{2}$ copolymer, and $\mathrm{LysM}_{2} \mathrm{G} / \mathrm{CatD}$ polymer against $T$. viride. Reproduced from Minamihata et al. (2021). Copyright 2021 with permission from the American Chemical Society (ACS) 
A
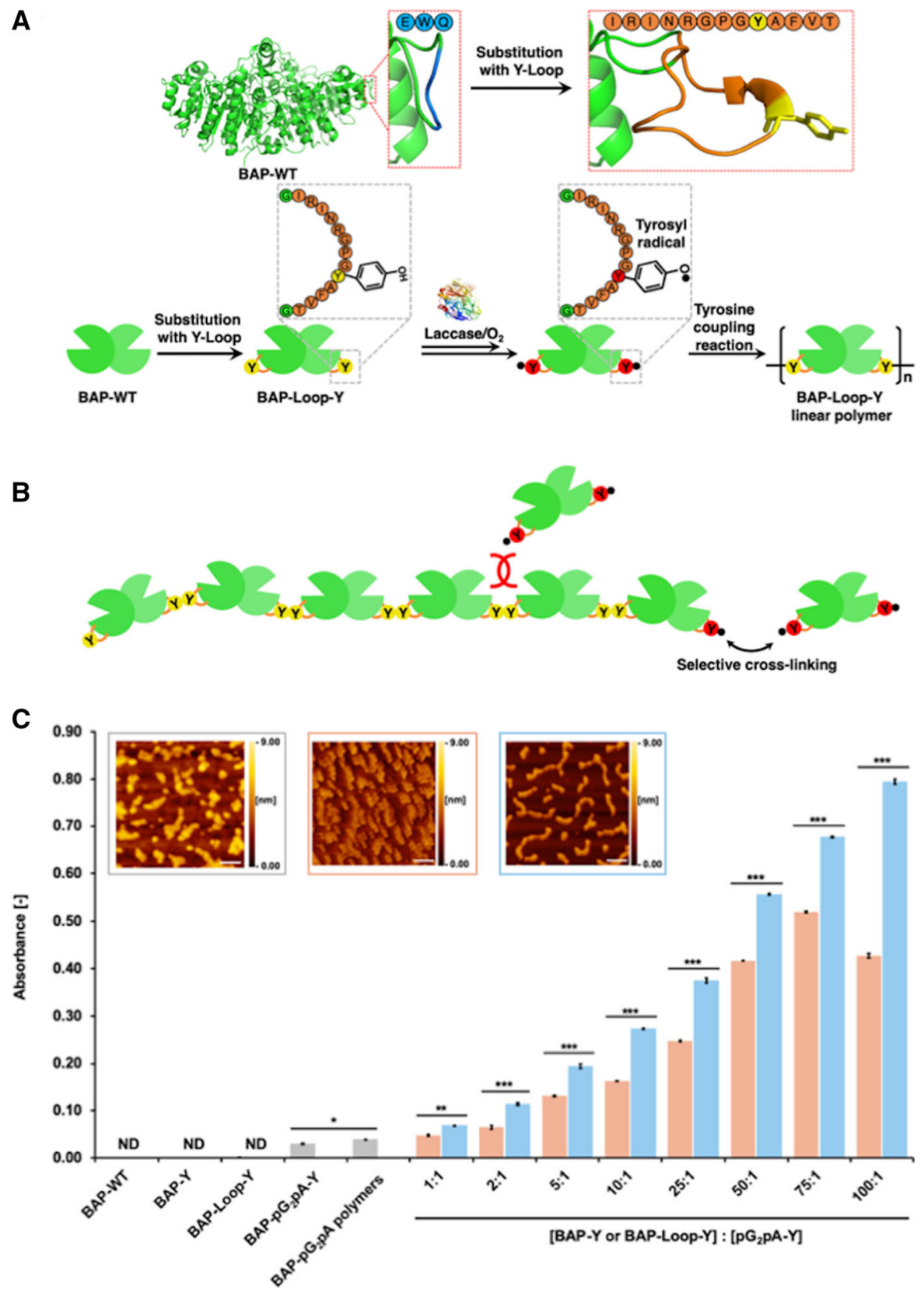

Fig. 7 A Strategy of BAP-Loop-Y construction; substitution of the BAP loop domain (219-221 aa) with a 13-mer Y-Loop (IRINRGPGYAFVT) peptide. TL recognizes and oxidizes phenolic moieties of tyrosine residues on the Y-Loop to form reactive free tyrosyl radicals, which then react with each other in a nonenzymatic way to form BAP-Loop-Y polymers. B Short and sterically hindered Y-Loop made the gap between the BAPLoop-Y units very close and prevented the formation of branches. C Results of the OVA-detecting ELISA using BAP and $\mathrm{pG}_{2} \mathrm{pA}-\mathrm{Y}$ copolymers prepared at various molar ratios. The concentration of OVA that coated the wells was $1 \mu \mathrm{g} / \mathrm{mL}$ in TBS (pH 7.4). ND: not detected. The boxes with different outline color presented the atomic force microscopy (AFM) results of the copolymers; $\mathrm{BAP}-\mathrm{pG}_{2} \mathrm{pA}-\mathrm{Y}$ polymers (grey), BAP-Y/pG 2 pA-Y copolymers (orange), and BAP-Loop-Y/ $\mathrm{pG}_{2} \mathrm{pA}-\mathrm{Y}$ copolymers (blue). Reproduced from Permana et al. (2020). Copyright 2020 with permission from the American Chemical Society (ACS) 
13 amino acids, IRINRGPGYAFVT, and the tyrosine residue can be recognized by laccase in the polymerization reaction. The phenolic moiety of the tyrosine residue of BAP-Loop-Y is recognized by TL to form free tyrosyl radicals that initiate the polymerization reaction of BAP-Loop-Y. This strategy is different from other reports by Kamiya Groups, where they usually used a long flexible tyrosine-containing peptide tag (Y-tags) at the $\mathrm{N}$ and/or C-terminus to perform HRP- or laccasecatalyzed crosslinking reactions (Permana et al. 2018, 2019). This is because long Y-tags usually form branched and globular structures of protein polymers, which are not preferable for use as protein probes in diagnostic applications. The globular polymeric proteins might be saturated and cause lower activity in diagnostic applications, such as enzyme-linked immunosorbent assay (ELISA). Thus, their new BAP polymerization strategy by engineering BAP using Y-Loop is expected to create a linear BAP polymer. The short and rigid structure of Y-Loop inhibited the formation of branches due to the steric hindrance between BAP units to form linear BAP-Loop-Y polymers (Fig. 7B). Moreover, TL-catalyzed copolymerization of BAP-Loop-Y with Y-tagged chimeric antibody binding proteins (ABPs), consisting of two molecules, protein $G$ (pG) and one molecule protein $\mathrm{A}(\mathrm{pA}), \mathrm{pG}_{2} \mathrm{pA}-\mathrm{Y}$, also resulted in the formation of linear BAP-Loop-Y/ $\mathrm{pG}_{2} \mathrm{pA}-\mathrm{Y}$ copolymers (blue box), which have different structures than $\mathrm{BAP}-\mathrm{Y} / \mathrm{pG}_{2} \mathrm{pA}-\mathrm{Y}$ copolymers (orange box) and $\mathrm{BAP}-\mathrm{pG}_{2} \mathrm{pA}-\mathrm{Y}$ polymers (genetically fused $\mathrm{BAP}$ and $\mathrm{pG}_{2} \mathrm{pA}-\mathrm{Y}$ ) (gray box) (Fig. 7C). Interestingly, different morphologies of copolymers resulted in differences in the enzymatic activity in the OVA-detecting ELISA. The linear BAP-Loop-Y/ $\mathrm{pG}_{2} \mathrm{pA}-\mathrm{Y}$ copolymers (blue bar) showed the highest absorbance in the OVA-detecting ELISA, suggesting that the structure of copolymers could be the most important factor in improving the activity and functionality of protein polymers. This strategy is promising and can contribute to the development of highly active protein polymers for diagnostic applications.

\section{Sortase A (SrtA)}

A common hydrolase used for protein crosslinking experiments is sortase, a calcium-dependent enzyme which catalyzes the crosslinking reaction of proteins that signal a specific sequence, LPXTG. Sortase A (SrtA) (EC 3.4.22.70) is the best example of a sortase isolated from Staphylococcus aureus and has been widely used by researchers to modify proteins (Spirig et al. 2011; Heck et al. 2013, 2014; Garg et al. 2018). However, SrtA is more appropriately defined as a transpeptidase. The cysteine residues on the active site of SrtA cleave the amide bond of Thr-Gly of LPXTG of the target protein to form an intermediate called protein-enzyme-thioester. Next, the amine as a nucleophile attacks the intermediate of the enzyme-acylprotein to form a peptide bond at $\mathrm{T}$ with $\mathrm{G}$, which eventually restores -LPXTGGGG- (SrtA recognition sequence). The amine group of the oligoglycine then catalyzes the discharge of the protein from SrtA. This mechanism, called sortagging and involving polyglycine, inspired researchers to design accurate substrates for SrtA-catalyzed crosslinking reactions.

An impressive study of the use of SrtA for preparing protein polymers or polyproteins was reported by the Rakshit Group. They developed an interesting method to create polyproteins on a specific surface by stapling one unit of POI at a time through covalent peptide bonds catalyzed by SrtA. To imitate the sortagging protocol through an in vitro reaction, they modified the POI recombinantly (Fig. 8A) by adding three Gly (3G) from $N$-terminal to $C$-terminal followed by SrtA recognition sequence (LPXTG) for "enzymatic stapling" (ES). Moreover, to inhibit the reactive nucleophile ( $3 \mathrm{G}$ at the $N$-terminal), the author added a detachable cap. Furthermore, a protease, TEV protease (TP), will recognize a heptameric peptide sequence (EXXYXQG) to perform "enzymatic cut" (EC) reaction resulting in the formation of QG site which leaves another $\mathrm{G}$ to be succeeded by the $3 \mathrm{G}$ 's at the $N$-terminal of POI. At the final step of SrtAcatalyzed sortagging trans-peptidation, the $4 \mathrm{G}$ 's in the sequence accommodate the rate of nucleophilic attack. Figure $8 \mathrm{~B}$ presents a schematic of the preparation of the polyprotein based on the strategy mentioned above. This strategy is interesting because it involves successive ES and EC, which can be used to create chimeric polyprotein constructs and can be applied to many recombinant POIs with minimal modifications at either the $N$ - or $C$-terminal.(Garg et al. 2018). 


\section{A For affinity purification TEV protease Nucleophile site cut site for sortagging 6x His-Tag-ENLYFQG GGG Protein Of Interest LPETGSS}

B
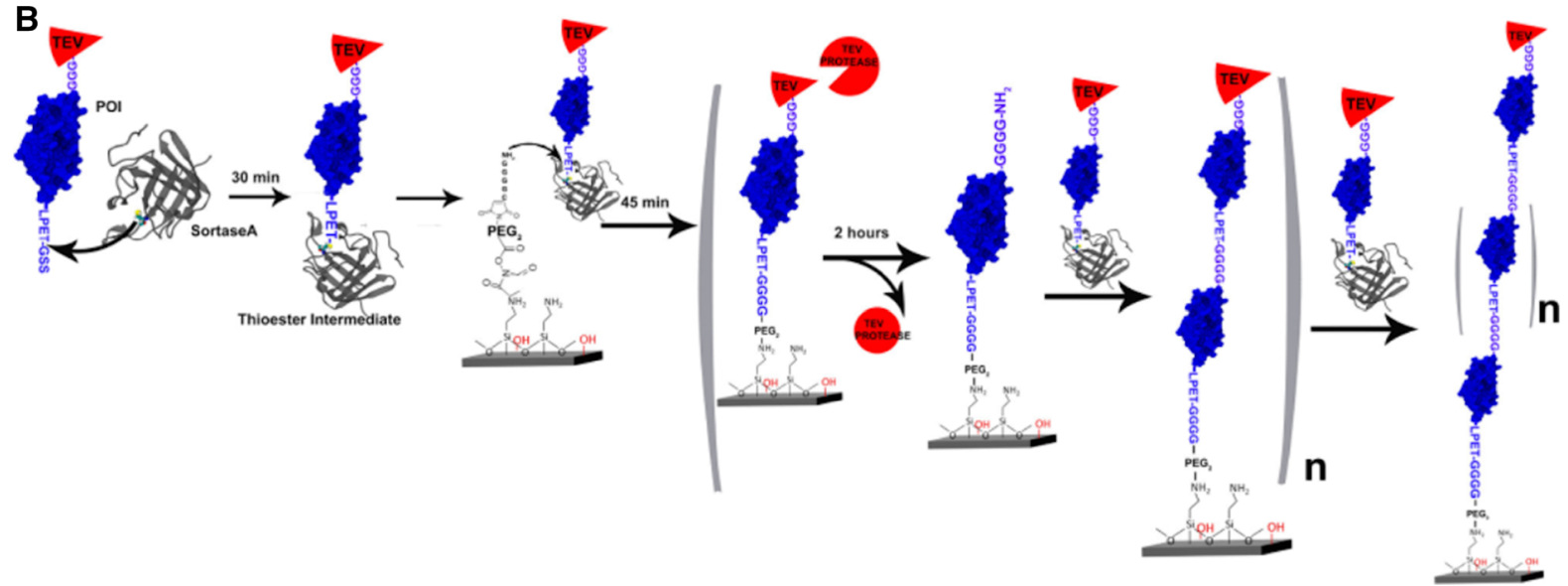

Fig. 8 Schematics of the enzymes-catalyzed synthesis of polyprotein on a solid surface. A Protein of interest (POI) which is designed in this study. The $N$-terminal has 6xHis-tag, three gycines ( $3 \mathrm{G}$ 's), and TEV protease cut site; $C$-terminal has LPETGSS (SrtA recognition site). B Firstly, POI and SrtA are reacted for $30 \mathrm{~min}$ to form the thioester intermediate. This step

Polymerization of protein through site-specific incorporation of non-natural amino acids (NNAAs)

Most protein polymers utilize natural amino acids to connect the protein units of the polymer backbone. This is more convenient because of the wide range of catalyst options used. However, to improve sitespecificity, some researchers have also applied NNAAs as targets for the crosslinking reaction. The protein polymerization reaction through site-specific incorporation of NNAAs offers site-specificity because NNAAs are only recognized by specific catalysts. The protein units were connected through covalent coupling between NNAAs (Albayrak and Swartz 2014; DeGruyter et al. 2017; Bartels et al. 2019). There are two existing strategies for NNAAs incorporation into proteins: first, the replacement of the aliphatic amino acids (menthionines, leucines, or isoleucines) with its NNAAs analog using special E. coli strains that can produce NNAAs and, second, NNAAs are introduced to amber stop codons using orthogonal tRNA (o-tRNA) and aminoacyl-tRNA synthetase (aaRS) (Albayrak and Swartz 2014). is called enzymatic stapling (ES). Secondly, surface is incubated with TEV protease (TP) for enzymatic cut (EC) for $2 \mathrm{~h}$ resulted in the polyglycine-exposed surface which ready to react with another thioester intermediates to meditate the next ES. Reproduced from Garg et al. (2018). Copyright 2018 with permission from the American Chemical Society (ACS)

An interesting study on the direct polymerization of proteins using two NNAS and copper-catalyzed azido-alkyne cycloaddition reaction (CuAAC) or click chemistry was reported by Albayrak and Swartz (2014) who modified superfolder green fluorescent protein (sfGFP) with two NNAAs: (1) p-azido-L-phenylalanine (pAzF) and (2) p-propargyloxy-L-phenylalanine (pPaF) (Fig. 9A) (Albayrak and Swartz 2014). $\mathrm{pAzF}$ and $\mathrm{pPaF}$ were introduced at several positions of amino acid positions 23, 39, and 15 by cell-free protein synthesis (CFPS). The polymerization of sfGFP23,39,151pAzF and sfGFP23,39,151pPaF was triggered by the presence of copper (I) ions $\left(\mathrm{Cu}^{+}\right)$(Fig. 9B). As a result, sfGFP containing two or three NNAAs was connected through CuAAC to form linear (two NNAAs at 23 and 39 positions) or branched (three NNAAs at 23, 39 , and 151 positions) protein polymers. The results of SDS-PAGE analysis also showed that sfGFP polymers were stuck in the stacking gel because of their very large size (Fig. 9C). Interestingly, even though the polymers could not be separated by single-step size-exclusion chromatography, the monomers were successfully separated from the sfGFP polymer mixture (Fig. 9D). The SDS-PAGE 
A<smiles>CC(C)Cc1ccc(C(N)=O)cc1</smiles><smiles>C=CCOc1ccc(CC(C)C)cc1</smiles>

B

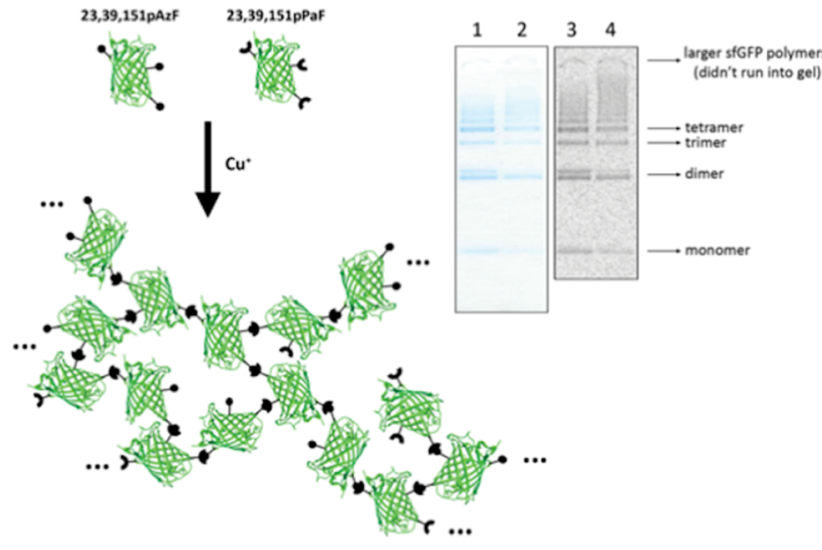

D

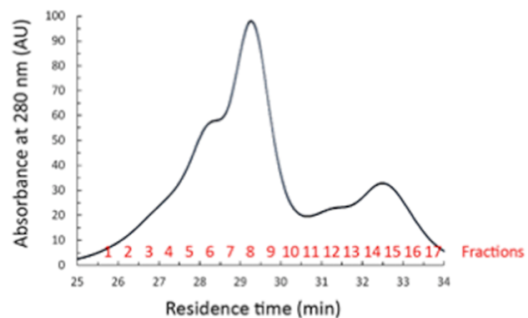

E

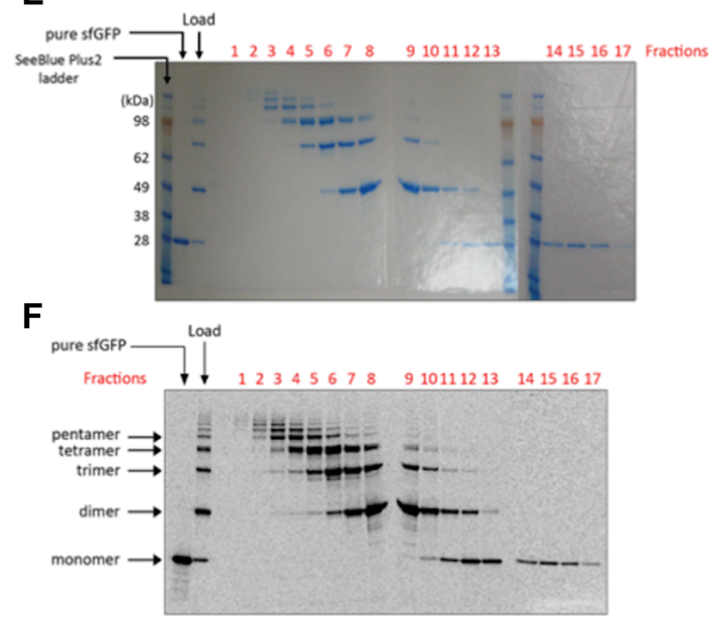

Fig. 9 Designed sfGFP used for $\mathrm{Cu}$-catalyzed azido-alkyne cycloaddition reaction (CuAAC) study. A Two non-natural amino acids (NNAAs) used in this study: (1) $p$-azido-Lphenylalanine (pAzF) and (2) p-propargyloxy-L-phenylalanine $(\mathrm{pPaF}) . \mathbf{B}$ polymerization reaction of the two sfGFPs in the presence of $\mathrm{Cu}^{+}$. C Results of SDS-PAGE analysis of the sfGFP polymers formed from the polymerization reaction of

(Fig. 9E) and autoradiography (Fig. 9F) analysis results suggested that $\sim 40 \%$ of the sfGFP monomer was polymerized, $\sim 40 \%$ formed dimers, $\sim 15 \%$ remained intact, and $\sim 5 \%$ was degraded. This strategy offers high site-specificity and versatility of coupling reactions that can be applied not only for the preparation of protein polymers but also for the formation of protein conjugates, biomaterials, and other protein-based products. However, the introduction of NNAAs requires careful consideration because of the activity changes that may occur in the NNAA-modified protein. For example, the activity of sfGFP23,39pPaF was only $83 \%$ of the specific activity of native sfGFP. Polymerized sfGFP retained approximately $78 \%$ of its specific activity compared to native sfGFP (Albayrak and Swartz 2014). In addition, the introduction of NNAAs may affect protein expression. A special strain of Escherichia coli is required for protein expression.
sfGFP23,39,151pAzF and sfGFP23,39,151pPaF. D Chromatogram of size-exclusion chromatography (SEC) of sfGFP polymers. E SDS-PAGE analysis of the SEC fractions from (D). F Autoradiography of the SEC fractions from (D). Reproduced from Albayrak and Swartz (2014). Copyright 2018 with permission from the American Chemical Society (ACS)

Cell-free protein synthesis is a good method for expressing NNAA-containing recombinant proteins, as reported in this study. Therefore, the use of NNAAs in the polymerization reaction of proteins is a good approach for preparing protein polymers with desired structures and functions.

Polymerization of protein through irreversible protein-peptide (SpyTag/SpyCatcher) interaction

Advances in molecular biology and protein engineering have made it possible to modify proteins with peptide tags for further reaction with enzymes or chemicals. Peptide tags are powerful tools for sitespecific protein modification; however, their interactions in the crosslinking reaction require a catalyst. The peptide tag interactions in the self-assembly reaction are typically weak and reversible. As an alternative, researchers discovered the $\mathrm{CnaB} 2$ domain, which is a 


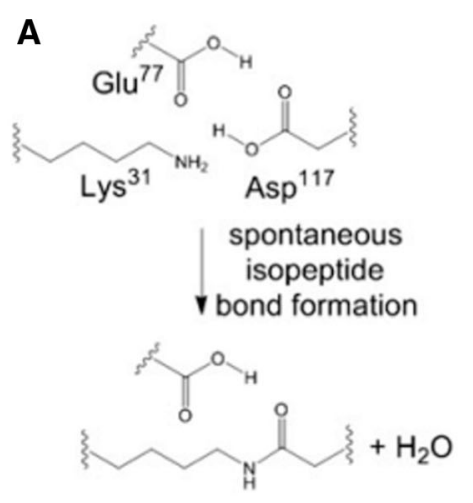

B

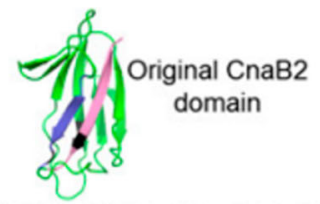

Split into 3 and rational engineering
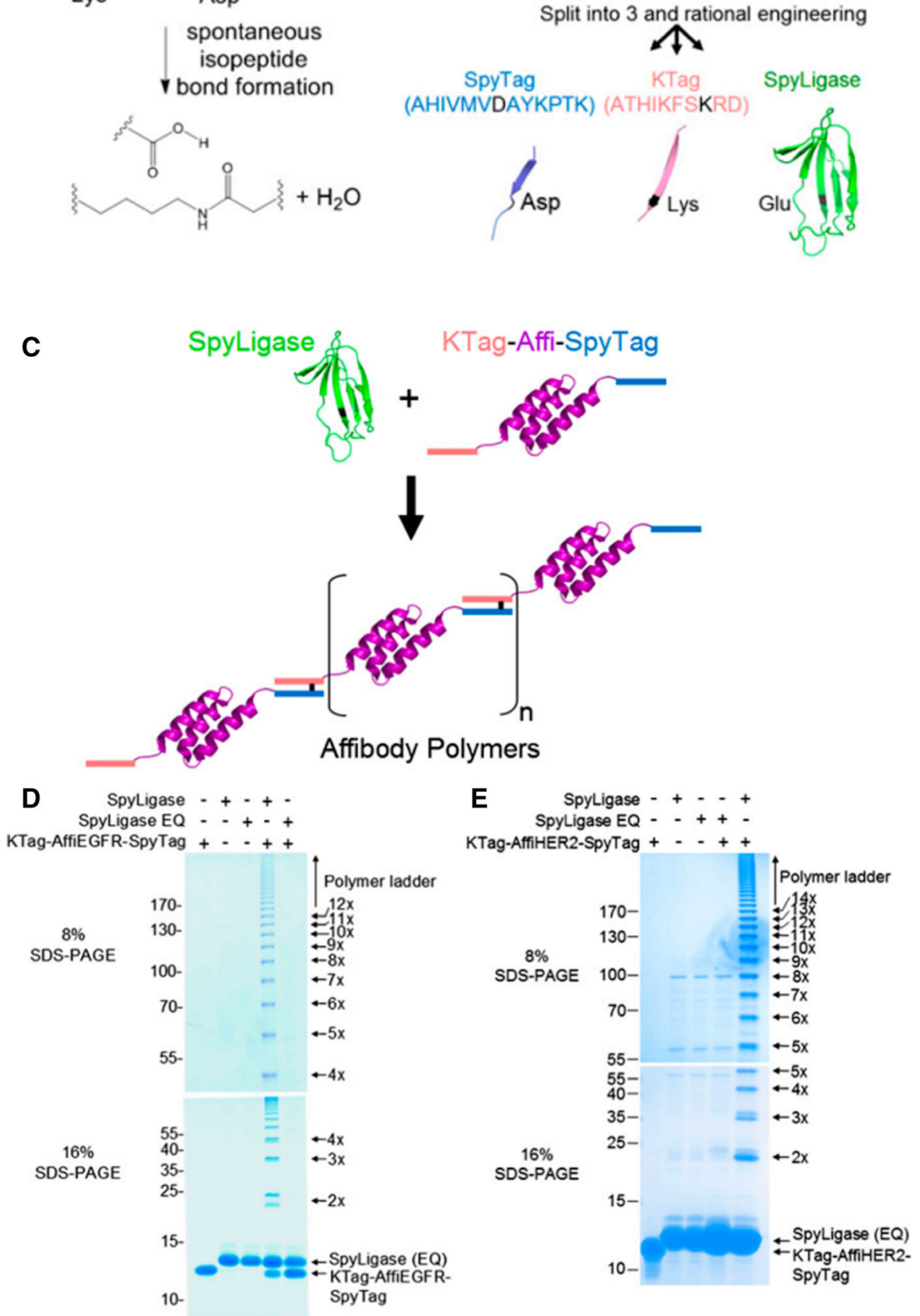

part of the fibronectin adhesion protein $\mathrm{FbaB}$ of Spontaneous isopeptide bond formation occurs in the Streptococcus pyogenes (Spy) (Fierer et al. 2014; Banerjee and Howarth 2018; Andersson et al. 2019). CnaB2 domain between Lys and Asp. Fierer et al. (2014) developed another active residue, Glu, at 
4Fig. 10 A Schematic reaction of spontaneous isopeptide bond formation of Lys and Asp in the presence of Glu. B The original CnaB2 was separated into three molecules: SpyTag (containing Asp residue), KTag (Lys residue), and SpyLigase (Glu residue). C Schematic reaction of the polymerization of affibody through isopeptide bond formation between SpyTag and KTag. D SDSPAGE analysis of the polymerization reaction of polymerized K-tag-AffiEGFR-SpyTag after $24 \mathrm{~h}$. E SDS-PAGE analysis of the polymerization reaction of polymerized K-tag-AffiHER2SpyTag after $48 \mathrm{~h}$. Reproduced from Fierer et al. (2014). Copyright 2014 with permission from the National Academy of Sciences (NAS)

position 77 of the amino acid (Fig. 10A). The CnaB2 domain can be separated into two parts: a protein domain called SpyCatcher and a peptide tag called SpyTag. Other active domains have also been developed by them; a SpyLigase, which contains Glu, SpyTag with Asp, and a K-tag with Lys residue (Fig. 10B). They engineered two kinds of K-tagAffibody-SpyTag monomers: K-tag-AffiEGFR-SpyTag and K-tag-AffiHER2-SpyTag to confirm the functionality and activity of the newly proposed SpyLigase and K-tag in the polymerization reaction of affibody (Fig. 10C) (Fierer et al. 2014). The K-tag binds to SpyTag to form affibody polymers in the presence of SpyLigase. The reactivity of K-tagAffiEGFR-SpyTag (Fig. 10D) and K-tag-AffiHER2SpyTag (Fig. 10E) against SpyLigase was the same. It takes 24 and $48 \mathrm{~h}$ to polymerize K-tag-AffiEGFRSpyTag and K-tag-AffiHER2-SpyTag, respectively, because of the spontaneous reaction of K-tag/SpyTag/ SpyLigase and the formation of isopeptide bonds. However, their reactivity against SpyLigase (mutation of $\mathrm{Glu}^{77}$ to Gln) was also same, they remained intact. The mutation on SpyLigase affected its activity in catalyzing the coupling of the K-tag and Spy-Tag. The polymerization of proteins through SpyTag/SpyCatcher or K-tag/SpyTag/SpyLigase is an impressive and interesting strategy that offers high site-specificity, spontaneity, and compatibility for a wide range of protein models. In some cases, the SpyTag/SpyCatcher interaction takes more time to polymerize the protein, as in this study. However, SpyTag/SpyCatcher is still a promising strategy for preparing protein polymers.

\section{Conclusions and future perspectives}

Protein multimerization and polymerization reactions are interesting and impressive strategies for protein functionalization with both having some advantages and disadvantages in the preparation of multimeric and polymeric proteins. Multimerization of proteins through tandem fusion is the most convenient because the designed multimeric proteins can be expressed in one expression cassette, without involving the formation of non-covalent and covalent bonds, and no catalyst is required. However, problems in protein expression and folding could be major problems in implementing this strategy for the preparation of multimeric proteins. Moreover, there are a limited number of proteins that can be fused into one expression cassette. Self-assembly is a better strategy for the preparation of multimeric proteins (Luo et al. 2014). Although it only offers a non-covalent bond to connect to the protein units, the multimerization reaction can be controlled and directed using specially designed protein monomers.

Protein polymerization is another strategy for the preparation of artificial protein polymers. The protein polymerization reaction commonly involves covalent bond formation to connect protein units of protein polymers. It is an interesting and promising approach to improve the functionality and activity of proteins in bioprocesses. Researchers can design the desired structures and characteristics of protein polymers for their designated reactions; this will be useful for the preparation of protein-based advanced materials. The protein polymerization reaction also facilitates the further development of artificial proteins and enzymes. The synergetic activity of the polymer protein units can improve the substrate conversion and product formation which will be beneficial in a bioprocess or specific enzymatic reaction on a small scale or even on a larger scale. Protein polymerization is a remarkable strategy for preparing effective antigens for vaccine development. Although there are no sufficient reports regarding the response of the immune system against polymeric antigens, this strategy is worth pursuing. Advances in the research and development of antibody-drug conjugates (ADCs) require enzymes to connect antibodies and drugs. Polymeric ADCs can be a novel approach for the development of ADCs (Sonzini et al. 2020). Some enzymes used in protein polymerization reactions are also good candidates for the preparation of ADCs. Therefore, the study of protein polymerization reactions using laccases reported in this review will 
contribute to the further development of protein polymers in the future.

Another useful application of multimeric or polymeric proteins is their functionality as probes in diagnostic applications (Permana et al. 2021). The activity of enzymes in the catalysis of substrate conversion has become a major feature of enzymes as probes in diagnostic applications such as enzyme immunoassays (EIA) and enzyme-based biosensors. The use of enzymes as probes in EIA includes two common examples of EIA: enzyme-linked immunosorbent assay (ELISA) and enzyme-multiplied immunoassay test (EMIT). The enzymes that are commonly used as probes or reporter enzymes in ELISA are alkaline phosphatases (AP), $\beta$-galactosidases, and peroxidases (Raja et al. 2011). Malate dehydrogenase is commonly used as a probe and is assayed for the detection of thyroxine; however, other proteins are also applicable as probes for bioimaging applications. Currently, researchers are trying to improve the functionality and activity of protein probes by conjugating enzymes with a binding or docking protein or fusing a unit of enzymes to prepare a multimeric or polymeric enzyme. Conjugation of some units of protein into the polymeric form could be a strategy to improve the functionality and activity of protein probes. Substrate conversion can become faster when protein polymers are used as probes (Permana et al. 2018, 2019, 2020).

Acknowledgements The authors are grateful to the Research Unit for Clean Technology, the National Research and Innovation Agency of Republic of Indonesia (BRIN) for the financial support. We thank Proofers (www.proofers.co.uk) for editing a draft of this manuscript.

Author contributions DP: Conceptualization, review outline design, visualization, writing-original draft, review, and editing. HEP: writing-review and editing. DD: Writingreview and editing. The manuscript was written through the contributions of all the authors. All authors contributed to the discussion of the paper and approved the final manuscript.

\section{Declarations}

Conflict of interest The authors declare that they have no competing financial interests or personal relationships that could have influenced the work reported in this paper.

\section{References}

Albayrak C, Swartz JR (2014) Direct polymerization of proteins. ACS Synth Biol 3:353-362. https://doi.org/10.1021/ $\operatorname{sb} 400116 x$

Andersson AMC, Buldun CM, Pattinson DJ et al (2019) SnoopLigase peptide-peptide conjugation enables modular vaccine assembly. Sci Rep. https://doi.org/10.1038/ s41598-019-40985-w

Bai Y, Luo Q, Zhang W et al (2013) Highly ordered protein nanorings designed by accurate control of glutathione S-transferase self-assembly. J Am Chem Soc 135:10966-10969. https://doi.org/10.1021/ja405519s

Banerjee A, Howarth M (2018) Nanoteamwork: covalent protein assembly beyond duets towards protein ensembles and orchestras. Curr Opin Biotechnol 51:16-23. https://doi.org/ 10.1016/j.copbio.2017.10.006

Bartels L, Ploegh HL, Spits H, Wagner K (2019) Preparation of bispecific antibody-protein adducts by site-specific chemoenzymatic conjugation. Methods 154:93-101. https://doi. org/10.1016/j.ymeth.2018.07.013

Buchert J, Ercili Cura D, Ma H et al (2010) Crosslinking food proteins for improved functionality. Annu Rev Food Sci Technol 1:113-138. https://doi.org/10.1146/annurev.food. 080708.100841

Bule P, Pires VM, Fontes CM, Alves VD (2018) Cellulosome assembly: paradigms are meant to be broken! Curr Opin Struct Biol 49:154-161. https://doi.org/10.1016/j.sbi.2018. 03.012

Campbell LA, Kodadek T, Brown KC (1998) Protein crosslinking mediated by metalloporphyrins. Bioorganic Med Chem 6:1301-1307. https://doi.org/10.1016/S09680896(98)00120-5

Chen R, Huang X, Xu H et al (2015) Plasmonic enzyme-linked immunosorbent assay using nanospherical brushes as a catalase container for colorimetric detection of ultralow concentrations of listeria monocytogenes. ACS Appl Mater Interfaces 7:28632-28639. https://doi.org/10.1021/acsami. 5 b10181

Chou KC (2020) Progresses in predicting post-translational modification. Int J Pept Res Ther 26:873-888. https://doi. org/10.1007/s10989-019-09893-5

DeGruyter JN, Malins LR, Baran PS (2017) Residue-specific peptide modification: a chemist's guide. Biochemistry 56:3863-3873. https://doi.org/10.1021/acs.biochem. $7 \mathrm{~b} 00536$

Desai A, Mitchison TJ (1997) Microtubule polymerization dynamics. Annu Rev Cell Dev Biol 13:83-117. https://doi. org/10.1146/annurev.cellbio.13.1.83

Desentis-Mendoza RM, Hernández-Sánchez H, Moreno A et al (2006) Enzymatic polymerization of phenolic compounds using laccase and tyrosinase from Ustilago maydis. Biomacromol 7:1845-1854. https://doi.org/10.1021/ bm060159p

Díaz-Rodríguez A, Davis BG (2011) Chemical modification in the creation of novel biocatalysts. Curr Opin Chem Biol 15:211-219. https://doi.org/10.1016/j.cbpa.2010.12.002

Domeradzka NE, Werten MWT, Wolf FA, de Vries R (2016) Protein crosslinking tools for the construction of 
nanomaterials. Curr Opin Biotechnol 39:61-67. https://doi. org/10.1016/j.copbio.2016.01.003

Elvin CM, Carr AG, Huson MG et al (2005) Synthesis and properties of crosslinked recombinant pro-resilin. Nature 437:999-1002. https://doi.org/10.1038/nature04085

Faccio G, Kämpf MM, Piatti C et al (2014) Tyrosinase-catalyzed site-specific immobilization of engineered C-phycocyanin to surface. Sci Rep 4:1-8. https://doi.org/10. 1038/srep05370

Falatach R, Li S, Sloane S et al (2015) Why synthesize proteinpolymer conjugates? The stability and activity of chymotrypsin-polymer bioconjugates synthesized by RAFT. Polymer (guildf) 72:382-386. https://doi.org/10.1016/j. polymer.2015.04.010

Fan L, Wang Y, Tuyishime P et al (2018) Engineering artificial fusion proteins for enhanced methanol bioconversion. ChemBioChem 19:2465-2471. https://doi.org/10.1002/ cbic. 201800424

Fegan A, Kumarapperuma SC, Wagner CR (2012) Chemically self-assembled antibody nanostructures as potential drug carriers. Mol Pharm 9:3218-3227. https://doi.org/10.1021/ mp300303k

Fierer JO, Veggiani G, Howarth M (2014) SpyLigase peptidepeptide ligation polymerizes affibodies to enhance magnetic cancer cell capture. Proc Natl Acad Sci U S A 111:E1176-E1181. https://doi.org/10.1073/pnas. 1315776111

Garg S, Singaraju GS, Yengkhom S, Rakshit S (2018) Tailored polyproteins using sequential staple and cut. Bioconjug Chem 29:1714-1719. https://doi.org/10.1021/acs. bioconjchem.8b00163

Granhøj J, Dimke H, Svenningsen P (2019) A bacterial display system for effective selection of protein-biotin ligase BirA variants with novel peptide specificity. Sci Rep 9:1-11. https://doi.org/10.1038/s41598-019-40984-x

Gunnoo SB, Madder A (2016) Bioconjugation - using selective chemistry to enhance the properties of proteins and peptides as therapeutics and carriers. Org Biomol Chem 64:4-17. https://doi.org/10.1039/C6OB00808A

Häkkinen A, Tran H, Yli-Harja O et al (2013) Effects of multimerization on the temporal variability of protein complex abundance. BMC Syst Biol 7:1-13. https://doi.org/10. 1186/1752-0509-7-S1-S3

Hashimoto K, Nishi H, Bryant S, Panchenko AR (2011) Caught in self-interaction: evolutionary and functional mechanisms of protein homooligomerization. Phys Biol 8:35007. https://doi.org/10.1088/1478-3975/8/3/035007

Hauke S, Best M, Schmidt TT et al (2014) Two-step protein labeling utilizing lipoic acid ligase and sonogashira crosscoupling. Bioconjug Chem 25:1632-1637. https://doi.org/ 10.1021/bc500349h

Heal WP, Wickramasinghe SR, Bowyer PW et al (2002) Sitespecific $\mathrm{N}$-terminal labelling of proteins in vitro and in vivo using $\mathrm{N}$-myristoyl transferase and bioorthogonal ligation chemistry. Chem Commun 8:480-482. https://doi.org/10. 1039/b716115h

Heck T, Faccio G, Richter M, Thöny-Meyer L (2013) Enzymecatalyzed protein crosslinking. Appl Microbiol Biotechnol 97:461-475. https://doi.org/10.1007/s00253-012-4569-z

Heck T, Pham P-H, Yerlikaya A et al (2014) Sortase A catalyzed reaction pathways: a comparative study with six SrtA variants. Catal Sci Technol 4:2946-2956. https://doi.org/ 10.1039/c4cy00347k

Hoffman EA, Frey BL, Smith LM, Auble DT (2015) Formaldehyde crosslinking: a tool for the study of chromatin complexes. J Biol Chem 290:26404-26411. https:// doi.org/10.1074/jbc.R115.651679

Hollmann F, Arends IWCE (2012) Enzyme initiated radical polymerizations. Polymers (basel) 4:759-793. https://doi. org/10.3390/polym4010759

Iturrate L, Sánchez-Moreno I, Oroz-Guinea I et al (2010) Preparation and characterization of a bifunctional aldolase/ kinase enzyme: a more efficient biocatalyst for $\mathrm{C}-\mathrm{C}$ bond formation. Chemistry 16:4018-4030. https://doi.org/10. 1002/chem.200903096

Jackson V (1999) Formaldehyde crosslinking for studying nucleosomal dynamics. Methods 17:125-139. https://doi. org/10.1006/meth.1998.0724

Janib SM, Gustafson JA, Minea RO et al (2014) Multimeric disintegrin protein polymer fusions that target tumor vasculature. Biomacromol 15:2347-2358. https://doi.org/10. 1021/bm401622y

Jia L, Minamihata K, Ichinose H et al (2017) Polymeric SpyCatcher scaffold enables bioconjugation in a ratio-controllable manner. Biotechnol J 12:1700195. https://doi.org/ 10.1002/biot.201700195

Joshi NS, Whitaker LR, Francis MB (2004) A three-component mannich-type reaction for selective tyrosine bioconjugation. J Am Chem Soc 126:15942-15943. https://doi.org/10. 1021/ja0439017

Jung B, Theato P (2013) Applications of chitosan and chitosan derivatives in drug delivery. Adv Polym Sci 253:37-70. https://doi.org/10.1007/12_2011_137

Jus S, Kokol V, Guebitz GM (2008) Tyrosinase-catalysed coupling of functional molecules onto protein fibres. Enzyme Microb Technol 42:535-542. https://doi.org/10. 1016/j.enzmictec.2008.02.012

Jus S, Stachel I, Schloegl W et al (2011) Crosslinking of collagen with laccases and tyrosinases. Mater Sci Eng C 31:1068-1077. https://doi.org/10.1016/j.msec.2011.03. 007

Kahn A, Moraïs S, Galanopoulou AP et al (2019) Creation of a functional hyperthermostable designer cellulosome. Biotechnol Biofuels 12:1-15. https://doi.org/10.1186/ s13068-019-1386-y

Kamiya N, Takazawa T, Tanaka T et al (2003) Site-specific crosslinking of functional proteins by transglutamination. Enzyme Microb Technol 33:492-496. https://doi.org/10. 1016/S0141-0229(03)00154-6

Kim K, Fancy DA, Carney D, Kodadek T (1999) Photoinduced protein crosslinking mediated by palladium porphyrins. J Am Chem Soc 121:11896-11897. https://doi.org/10. 1021/ja9916355

Kitaoka M, Mitsumori M, Hayashi K et al (2012) Transglutaminase-mediated in situ hybridization (TransISH) system: a new methodology for simplified mRNA detection. Anal Chem 84:5885-5891. https://doi.org/10.1021/ ac2034198

Lan G, Fan Q, Liu Y et al (2015) Rhamnolipid production from waste cooking oil using Pseudomonas SWP-4. Biochem Eng J 101:44-54. https://doi.org/10.1016/j.bej.2015.05. 001 
Leitner A, Walzthoeni T, Aebersold R (2014) Lysine-specific chemical crosslinking of protein complexes and identification of crosslinking sites using LC-MS/MS and the xQuest/xProphet software pipeline. Nat Protoc 9:120-137. https://doi.org/10.1038/nprot.2013.168

Li L, Kiick KL (2013) Resilin-based materials for biomedical applications. ACS Macro Lett 2:635-640. https://doi.org/ 10.1021/mz4002194

Lobba MJ, Fellmann C, Marmelstein AM et al (2020) Sitespecific bioconjugation through enzyme-catalyzed tyrosine-cysteine bond formation. ACS Cent Sci 6:1564-1571. https://doi.org/10.1021/acscentsci.0c00940

Luo Q, Dong Z, Hou C, Liu J (2014) Protein-based supramolecular polymers: progress and prospect. Chem Commun 50:9997-10007. https://doi.org/10.1039/ c4cc03143a

Ma H, Forssell P, Partanen R et al (2011) Improving laccase catalyzed crosslinking of whey protein isolate and their application as emulsifiers. J Agric Food Chem 59:1406-1414. https://doi.org/10.1021/jf103591p

Masri MS, Friedman M (1988) Protein reactions with methyl and ethyl vinyl sulfones. J Protein Chem 7:49-54

Mattinen M-LL, Hellman M, Permi P et al (2006) Effect of protein structure on laccase-catalyzed protein oligomerization. J Agric Food Chem 54:8883-8890. https://doi.org/ 10.1021/jf062397h

Mattinen M, Lantto R, Selinheimo E et al (2008) Oxidation of peptides and proteins by Trichoderma reesei and Agaricus bisporus tyrosinases. J Biotechnol 133:395-402. https:// doi.org/10.1016/j.jbiotec.2007.10.009

Milczek EM (2018) Commercial applications for enzyme-mediated protein conjugation: new developments in enzymatic processes to deliver functionalized proteins on the commercial scale. Chem Rev 118:119-141. https://doi.org/ 10.1021/acs.chemrev.6b00832

Minamihata K, Goto M, Kamiya N (2011) Site-specific protein crosslinking by peroxidase-catalyzed activation of a tyrosine-containing peptide tag. Bioconjug Chem 22:74-81. https://doi.org/10.1021/bc1003982

Minamihata K, Goto M, Kamiya N (2012) Control of a tyrosyl radical mediated protein crosslinking reaction by electrostatic interaction. Bioconjug Chem 23:1600-1609. https:// doi.org/10.1021/bc300137s

Minamihata K, Goto M, Kamiya N (2015) Site-specific conjugation of an antibody-binding protein catalyzed by horseradish peroxidase creates a multivalent protein conjugate with high affinity to IgG. Biotechnol J 10:222-226. https:// doi.org/10.1002/biot.201400512

Minamihata K, Tanaka Y, Santoso P et al (2021) Orthogonal enzymatic conjugation reactions create chitin binding domain grafted chitinase polymers with enhanced antifungal activity. Bioconjug Chem 32:1688-1698. https:// doi.org/10.1021/acs.bioconjchem.1c00235

Minamihata K, Yamaguchi S, Nakajima K, Nagamune T (2016) Tyrosine coupling creates a hyperbranched multivalent protein polymer using horseradish peroxidase via bipolar conjugation points. Bioconjug Chem 27:1348-1359. https://doi.org/10.1021/acs.bioconjchem.6b00138

Mogilevsky CS, Lobba MJ, Brauer DD et al (2021) Synthesis of multi-protein complexes through charge-directed sequential activation of tyrosine residues. J Am Chem Soc. https://doi.org/10.1021/jacs.1c03079

Moreira Teixeira LS, Feijen J, van Blitterswijk CA et al (2012) Enzyme-catalyzed crosslinkable hydrogels: Emerging strategies for tissue engineering. Biomaterials 33:1281-1290. https://doi.org/10.1016/j.biomaterials. 2011.10.067

Mori Y, Goto M, Kamiya N (2011) Transglutaminase-mediated internal protein labeling with a designed peptide loop. Biochem Biophys Res Commun 410:829-833. https://doi. org/10.1016/j.bbrc.2011.06.073

Mori Y, Wakabayashi R, Goto M, Kamiya N (2013) Protein supramolecular complex formation by site- specific avidin-biotin interactions. Org Biomol Chem 11:914-922. https://doi.org/10.1039/c2ob26625c

Müller MK, Petkau K, Brunsveld L (2011) Protein assembly along a supramolecular wire. Chem Commun 47:310-312. https://doi.org/10.1039/c0cc02084b

Onoda A, Inoue N, Sumiyoshi E, Hayashi T (2020) Triazolecarbaldehyde reagents for one-step $\mathrm{N}$-terminal protein modification. ChemBioChem 21:1274-1278. https://doi. org/10.1002/cbic. 201900692

Partlow BP, Applegate MB, Omenetto FG, Kaplan DL (2016) Dityrosine crosslinking in designing biomaterials. ACS Biomater Sci Eng 2:2108-2121. https://doi.org/10.1021/ acsbiomaterials.6b00454

Pei Z, Anderson H, Myrskog A et al (2010) Optimizing immobilization on two-dimensional carboxyl surface: $\mathrm{pH}$ dependence of antibody orientation and antigen binding capacity. Anal Biochem 398:161-168. https://doi.org/10. 1016/j.ab.2009.11.038

Permana D, Minamihata K, Goto M, Kamiya N (2018) Laccasecatalyzed bioconjugation of tyrosine-tagged functional proteins. J Biosci Bioeng 126:559-566. https://doi.org/10. 1016/j.jbiosc.2018.05.013

Permana D, Minamihata K, Tatsuke T et al (2019) Polymerization of horseradish peroxidase by a laccase-catalyzed tyrosine coupling reaction. Biotechnol J 14:1800531. https://doi.org/10.1002/biot.201800531

Permana D, Minamihata K, Sato R et al (2020) Linear polymerization of protein by sterically controlled enzymatic crosslinking with a tyrosine-containing peptide loop. ACS Omega 5:5160-5169. https://doi.org/10.1021/acsomega. 9b04163

Permana D, Minamihata K, Goto M, Kamiya N (2021) Strategies for making multimeric and polymeric bifunctional protein conjugates and their applications as bioanalytical Tools. Anal Sci 37:425-437. https://doi.org/10.2116/ analsci.20SCR07

Pieters BJGE, Van Eldijk MB, Nolte RJM, Mecinović J (2016) Natural supramolecular protein assemblies. Chem Soc Rev 45:24-39. https://doi.org/10.1039/c5cs00157a

Rabuka D (2010) Chemoenzymatic methods for site-specific protein modification. Curr Opin Chem Biol 14:790-796. https://doi.org/10.1016/j.cbpa.2010.09.020

Raja MMM, Raja A, Imran MM et al (2011) Enzymes application in diagnostic prospects. Biotechnology 10:51-59. https://doi.org/10.3923/biotech.2011.51.59

Rizk M, Antranikian G, Elleuche S (2012) End-to-end gene fusions and their impact on the production of multifunctional biomass degrading enzymes. Biochem Biophys Res 
Commun 428:1-5. https://doi.org/10.1016/j.bbrc.2012.09. 142

Roberts JJ, Naudiyal P, Lim KS et al (2016) A comparative study of enzyme initiators for crosslinking phenol-functionalized hydrogels for cell encapsulation. Biomater Res 20:1-12. https://doi.org/10.1186/s40824-016-0077-z

Roeser D, Preusser-Kunze A, Schmidt B et al (2006) A general binding mechanism for all human sulfatases by the formylglycine-generating enzyme. Proc Natl Acad Sci U S A 103:81-86. https://doi.org/10.1073/pnas.0507592102

Roll-Mecak A (2020) The Tubulin code in microtubule dynamics and information encoding. Dev Cell 54:7-20. https://doi.org/10.1016/j.devcel.2020.06.008

Roy JJ, Abraham TE (2006) Preparation and characterization of cross-linked enzyme crystals of laccase. J Mol Catal B Enzym 38:31-36. https://doi.org/10.1016/j.molcatb.2005. 11.001

Rullán-Lind C, Pietri RB, Vázquez-Cintrón M, Baerga-Ortiz A (2018) Fused dimerization increases expression, solubility, and activity of bacterial dehydratase enzymes. Protein Sci 27:969-975. https://doi.org/10.1002/pro.3404

Sato R, Minamihata K, Wakabayashi R et al (2020) PolyTag: a peptide tag that affords scaffold-less covalent protein assembly catalyzed by microbial transglutaminase. Anal Biochem 600:113700. https://doi.org/10.1016/j.ab.2020. 113700

Selinheimo E, Autio K, Kruus K, Buchert J (2007) Elucidating the mechanism of laccase and tyrosinase in wheat bread making. J Agric Food Chem 55:6357-6365. https://doi.org/ 10.1021/jf0703349

Selinheimo E, Lampila P, Mattinen M-L, Buchert J (2008) Formation of protein-oligosaccharide conjugates by laccase and tyrosinase. J Agric Food Chem 56:3118-3128. https://doi.org/10.1021/Jf0730791

Silva CJSM, Sousa F, Gübitz G, Cavaco-Paulo A (2004) Chemical modifications on proteins using glutaraldehyde. Food Technol Biotechnol 42:51-56

Smith MEB, Schumacher FF, Ryan CP et al (2010) Protein modification, bioconjugation, and disulfide bridging using bromomaleimides. J Am Chem Soc 132:1960-1965. https://doi.org/10.1021/ja908610s

Sonzini S, Greco ML, Cailleau T et al (2020) Improved physical stability of an antibody-drug conjugate using host-guest chemistry. Bioconjug Chem 31:123-129. https://doi.org/ 10.1021/acs.bioconjchem.9b00809

Spirig T, Weiner EM, Clubb RT (2011) Sortase enzymes in Gram-positive bacteria. Mol Microbiol 82:1044-1059. https://doi.org/10.1111/j.1365-2958.2011.07887.x

Stephanopoulos N, Francis MB (2011) Choosing an effective protein bioconjugation strategy. Nat Chem Biol 7:876-884. https://doi.org/10.1038/nchembio.720

Su RSC, Kim Y, Liu JC (2014) Resilin: protein-based elastomeric biomaterials. Acta Biomater 10:1601-1611. https://doi.org/10.1016/j.actbio.2013.06.038
Takahara M, Kamiya N (2019) Synthetic strategies for artificial lipidation of functional proteins. Chem Eur J 26:4645-4655. https://doi.org/10.1002/chem.201904568

Tang H, Wang J, Wang S et al (2018) Efficient yeast surfacedisplay of novel complex synthetic cellulosomes. Microb Cell Fact 17:1-13. https://doi.org/10.1186/s12934-0180971-2

Tominaga J, Kamiya N, Goto M (2007) An enzyme-labeled protein polymer bearing pendent haptens. Bioconjug $\mathrm{Chem}$ 18:860-865. https://doi.org/10.1021/bc060161d

Tu C, Zhu L, Li P et al (2011) Supramolecular polymeric micelles by the host-guest interaction of star-like calix[4]arene and chlorin e6 for photodynamic therapy. Chem Commun 47:6063-6065. https://doi.org/10.1039/ c0cc05662f

Viljanen J, Tegler L, Broo KS (2004) Combinatorial chemical reengineering of the alpha class glutathione transferases. Bioconjug Chem 15:718-727

Wakabayashi R, Yahiro K, Hayashi K et al (2017) Proteingrafted polymers prepared through a site-specific conjugation by microbial transglutaminase for an immunosorbent assay. Biomacromol 18:422-430. https://doi.org/10. 1021/acs.biomac.6b01538

Wang Z, Wang Z, Yuan L et al (2016) Bioinspired high resilient elastomers to mimic resilin. ACS Macro Lett 5:220-223. https://doi.org/10.1021/acsmacrolett.5b00843

Wang T, Fan X, Hou C, Liu J (2018) Design of artificial enzymes by supramolecular strategies. Curr Opin Struct Biol 51:19-27. https://doi.org/10.1016/j.sbi.2018.02.003

Wedrychowski A, Schmidt WN, Hnilica LS (1986) The in vivo crosslinking of proteins and DNA by heavy metals. J Biol Chem 261:3370-3376

Yang YJ, Holmberg AL, Olsen BD (2017) Artificially engineered protein polymers. Annu Rev Chem Biomol Eng 8:549-575. https://doi.org/10.1146/annurev-chembioeng060816-101620

Yin L, Guo X, Liu L et al (2018) Self-assembled multimericenzyme nanoreactor for robust and efficient biocatalysis. ACS Biomater Sci Eng 4:2095-2099. https://doi.org/10. 1021/acsbiomaterials.8b00279

Yu K, Liu C, Kim BG, Lee DY (2015) Synthetic fusion protein design and applications. Biotechnol Adv 33:155-164. https://doi.org/10.1016/j.biotechadv.2014.11.005

Zhang C, Gao F, Wu W et al (2019) Enzyme-driven membranetargeted chimeric peptide for enhanced tumor photodynamic immunotherapy. ACS Nano 13:11249-11262. https://doi.org/10.1021/acsnano.9b04315

Publisher's Note Springer Nature remains neutral with regard to jurisdictional claims in published maps and institutional affiliations. 